\title{
دور المناخ الأسري في العلاقة بين التفكير الأخلاقي والاتجاه نحو التطرف الفكري لدى عينة من طالبات جامعة الملك خالد
}

\author{
صبحية أحمد عبد القادر محمد \\ أستاذ مساعد بقسم علم النفس- كلية التربية- جامعة الملك خالد- السعودية \\ drsobhia2010@gmail.com
}




\title{
دور المناخ الأسري في العلاقة بين التفكير الأخلاقي و الاتجاه نحو التطرف الفكري لدى عينة من طالبات جامعة الملك خالد
}

\author{
صبحية أحمدل عبد القادر محممد \\ أستاذ مساعد بقسم علم النفس- كلية التربية- جامعة الملك خالد- السعودية \\ drsobhia2010@gmail.com
}

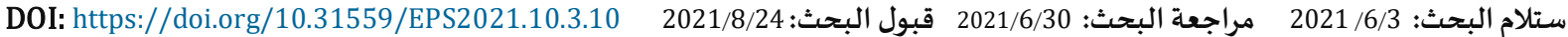

هدفت الدراسة إلى التعرف على دور المناخ الأسري في العلاقة بين التفكير الأخلاقي والاتجاه نحو التطرف الفكري لدى عينة من طالبات جامعة الملك خالد، شملت الدراسة على (250) طالبة من تخصصيات علمية وأدبية مختلفة، وتم تطبيق كل من الأدوات التالية: مقياس كل من

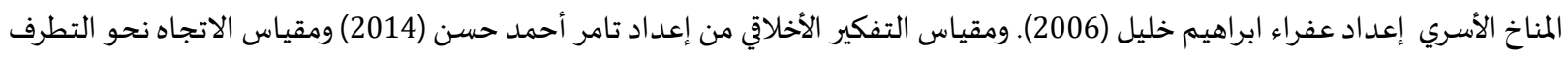
الفكري من إعداد محمد أبو دوابة (2012). وأسفرت الدراسة عن النتائج التالية: يوجد مستوى التفكير الأخلاقي مرتفع لدى طالبات جامعة إنات الملك خالد. ويوجد مستوى الاتجاه نحو التطرف الفكري متوسط لدى طالبات جامعة الملك خالد ـ كما توجد علاقة ارتباطية موجبة ذات دلالة إحصائية بين المناخ الأسري والتفكير الأخلاقي. وعلاقة ارتباطية موجبة ذات دلالة إحصائية بين المناخ الأسري والتطرف الفكري لدى عينة

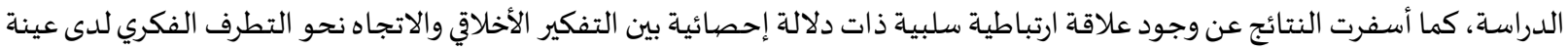

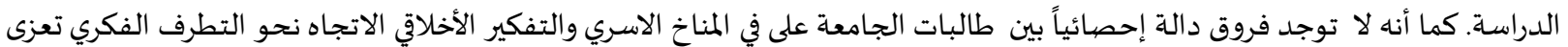

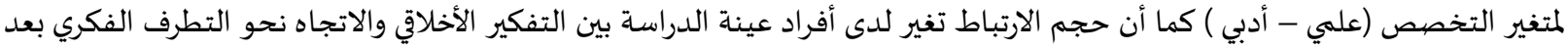

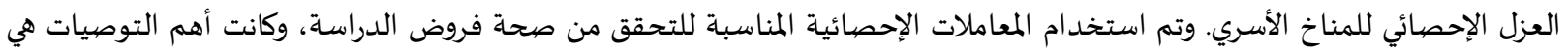
الاستمرار في العناية بالجانب الأخلاقي لدى طالبات الجامعة. الكلمات المفتاحية: مناخ أسري؛ تفكير أخلاقي؛ طالبات الجامعة.

يعيش الإنسان منذ ولادته وحتي مماته مع أشكالاً عديدة من السياقات، لكل سياق دوراً في تشكيل بنيانه النفسي ومنظومة افكاره ومعتقد اته، وتعد

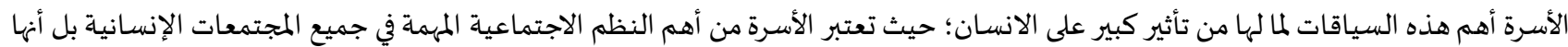

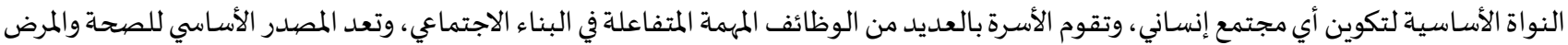

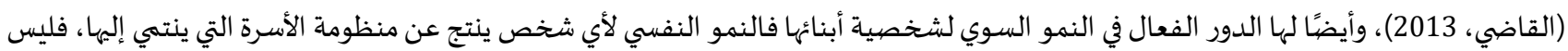

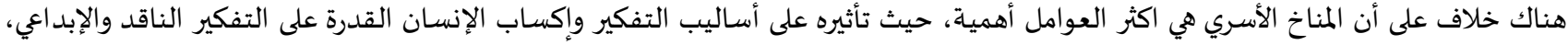

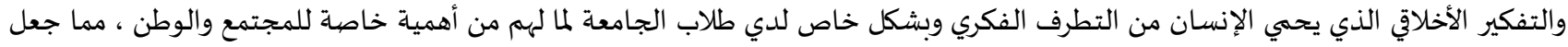
متغيرات مثل المناخ الأسري والتفكير الأخلاقي والتطرف الفكري من أهم الموضوعات التي تساعدنا في فهم التفاعل القائم بين الفرد والإطار الحضاري مني الحئ

" هذا البحث تم دعمه من خلال البرنامج البحثي العام بعمادة البحث العلمي - جامعة الملك خالد- المملكة العربية السعودية (بالرقم:G.R.P-392-42) 
الذي يعيش فياه، فمع تعقد الحياة الحديثة والتطور الهائل السريع أصبح الإانسان يواجه العديد من المواقف التي تهدد حياته ومستقبله وتزيد من

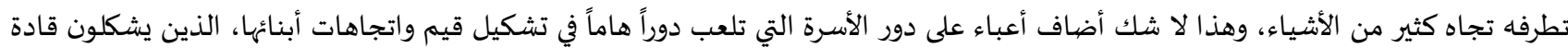
المستقبل وعماد الوطن، ولذلك تهتم الدول في شتى أنحاء العالم وفي المجتمعات المختلفة بفئة طلاب الجامعة وذلك من خلال فلسفات وأفكار ترتكز في المقام الأول على تحسين ورفع مستوى مناخهم الأسري ورفع مستوى تفكيرهم الأخلاقي (الرشدان، 2005)، (عبارة، 2018)، وزيادة انتمائهم لهذا الوطن الوطن عن طريق احتوائهم وتوفير السبل الإيجابية والمواتية لإشباع حاجاتهم وتحقيق مطالبهم وفتح قنوات الحوار معهم لمناقشة مشكلاتهم ومحاولة إيجاد

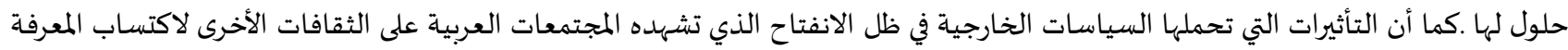

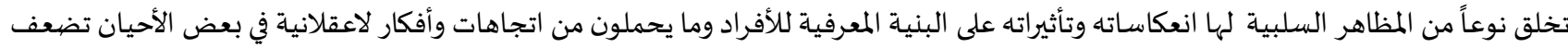

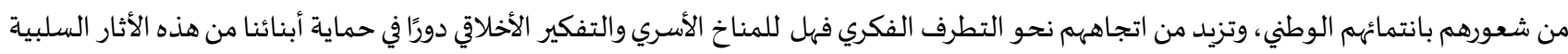

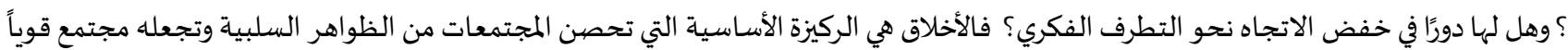

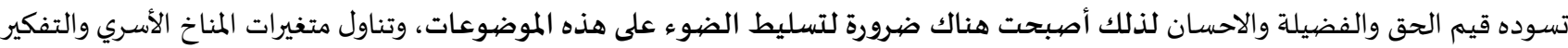
الأخلاقي والتطرف الفكري للبحث والدرواسة.

1.1. 1 مشكلة الدراسـة:

لاحظت الباحثة من خلال اطلاعها على بعض البحوث والدراسات النفسية والاجتماعية وفي حدود ما تم حصره، أنه توجد ثفرة حيث؛ لم يتم العثور على دراسة نفسية واحدة تعلن أن هدفها هو دراسـة كل من المناخ الأسري والتفكير الأخلاقي وعلاقتهما بالاتجاه نحو التطرف الفكري لدهي الدى عينة من من

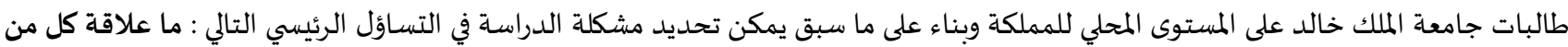

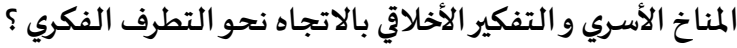

ويتفرع من هذا التساؤل الرئيسي التساؤلات الفرعية التالية:

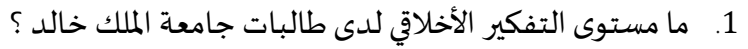

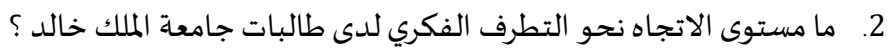

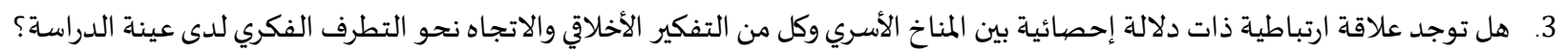

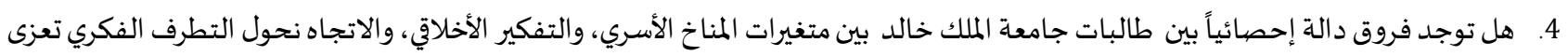

$$
\text { لمتفير التخصص (علمي- أدبي ) ؟ }
$$

5. هل يتغير حجم الارتباط لدى أفراد عينة الدراسة بين التفكير الأخلاقي والاتجاه نحو التطرف الفكري بعد العزل الإحصائي للمناخ الأسري؟

2.1 2. أهداف الدراسـة:

تهدف الدراسـة الى الكشف عن:

1. العلاقة بين كل من المناخ الأسري والتفكير الأخلاقي والاتجاه نحو التطرف الفكري لدى عينة الدراسة. 2. عما إذا كانت توجد فروق دالة إحصائياً بين طالبات الجامعة في المناخ الأسري والتفكير الأخلاقي والاتجاه نحو التطرف الفكري تعزى لمتغير التخصص (علمي- أدبي ). 3. تتغير حجم الارتباط لدى أفراد عينة الدراسة بين التفكير الأخلاقي والاتجاه نحو التطرف الفكري بعد العزل الإحصائي للمناخ الأسري.

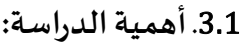

• تكمن أهمية الدراسة في كونها الدراسة المحلية العربية الأولى على حد علم الباحثة التي تناولت الكشف عن علاقة كل من المناخ الأسري والتفكير الأخلاقي والاتجاه نحو التطرف الفكري. كما ترجع اهمية الدراسة أهها ركزت على مرحلة الشباب ويمثلها طلاب الجامعة وتعد أكثر المراحل أهمية في حياة الفرد التي تتشكل فيها هويته ومستقبله وتفاعلاته مع العالم الآخر، وتمثل تلك الفئة الشريحة الأكبر في المجتمع السعودي المعرضة إلى الاضطرابات النفسية والصراع النفسي بسب الهب

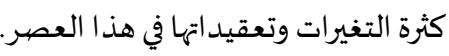
تعود أهمية الدراسة إلى محاول الكشف عن أهمية الدور الذي يلعبه كل من المناخ الأسري والتفكير الأخلاقي في خفض الاتجاه نحو التطرف الفكري 
تتمثل بتوفير قدر مناسب من البيانات والمعلومات عن طبيعة المناخ الأسري والتفكير الأخلاقي والاتجاه نحو التطرف الفكري ومن ثم تزويد

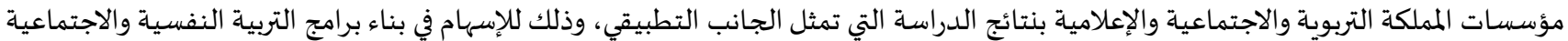

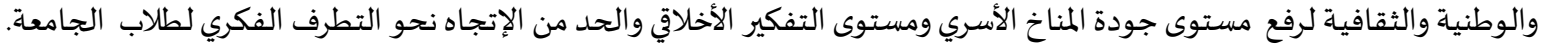

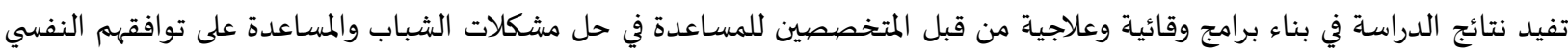

والاجتماعي.

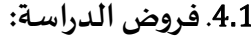

1. توجد علاقة ارتباطية ذات دلالة إحصائية بين المناخ الأسري وكل من التفكير الأخلاقي والاتجاه نحو التطرف الفكري لدى عينة الدراسة.

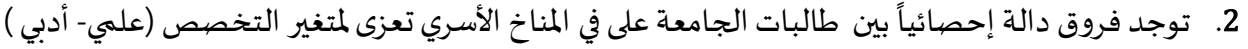

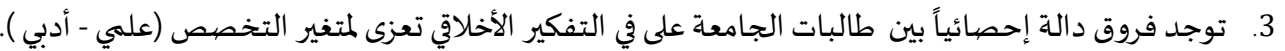

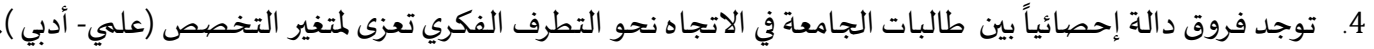

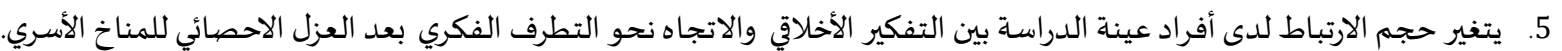

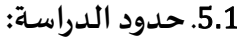

• الحدود الموضوعية: المناخ الأسري وعلاقته بكل من التفكير الأخلاقي وبالاتجاه نحو التطرف الفكري لدى عينة من طالبات جامعة الملك خالد. هالحدود المكانية: يمثل المجال المكاني لهذه الدراسة؛ جامعة الملك خالد. الحدود البشرية: يمثل المجال البشري لهذه الدراسة عينة من طالبات الجامعة قوامها (250) طالبة، مقسمة إلى (118) طالبة من الكليات العلمياة،(132) طالبة من الكليات الادبية بجامعة الملك خالد. الحدود الزمنية: إستغرق إعداد الدراسـة (الجزء النظري والعملي) 6 أشهر وقد تم تطبيق المقاييس في الفصل الدراسي الثاني من العام الدراسي

$1442-1441$

\section{2. الإطار النظري ومصطلحات الدراسـة:}

1.2. المناخ الأسري:

إن الأسرة هي العمود الفقري في تأسيس الملامح الأولى للفرد، وما سيكون عليه مستقبلاً، فالفرد منذ ولادته يراقب سلوك أسرته ويتعلم منها، ويستمر

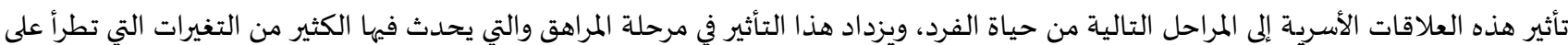

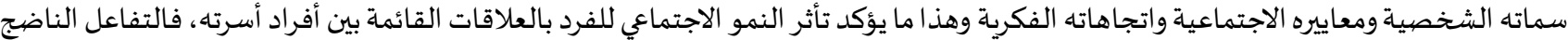

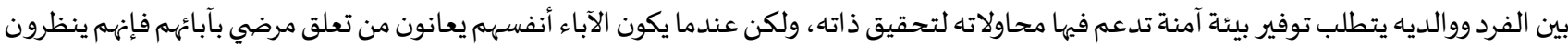
إليه على أنه امتداد لأنفسهم ويشعرون بأن لهم الحق في السيطرة عليه وامتلاكه، وبذلك يعوق الوالدان تكوين شخصية مستقلة للمراهق

2006) (خليل، (Coleman,2014,59) إن المناخ الأسري يسهم في التأثير على شخصية الأبناء، ويعد المناخ الأسري من أبرز ما يؤثر في سلوكهم، وضمن هذا المناخ يتعلم الأبناء كيف يعبرون

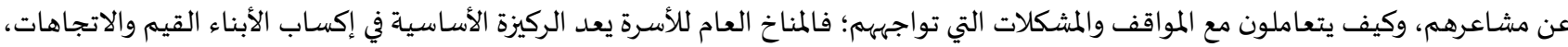

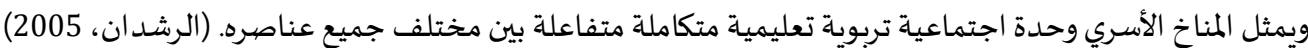

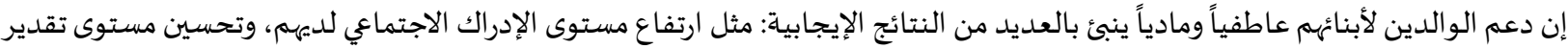

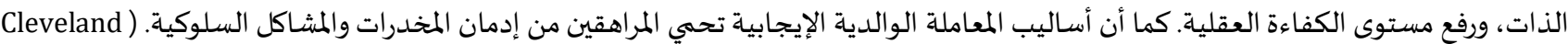
(et al, 2005 إن لمفهوم المناخ الأسري العديد من التعريفات، وذلك تبعاً لوجهات النظر في هذا المجال، عرفه كفافي (1999: 28) بأنه: "الجو الذي يسود الأسرة استنادا لطبيعة العلاقات الإنسانية والاجتماعية التي تربط بين أفراده. كما عرف خليل (2006: 31) المناخ الأسري بأنه: "الطابع العام للحياة الأسرية الذي

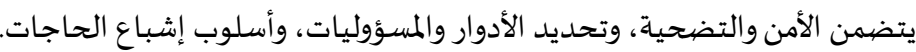
تتبنى الباحثة التعريف الاجر ائي للمناخ الأسري ل(خليل، 2006) "بأنه الطابع العام للحياة الأسرية من حيث توفر الأمان والتعاون والتضحية

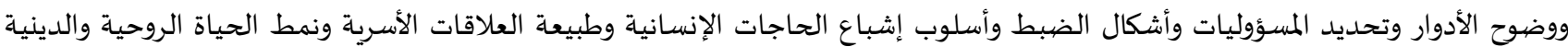
والخلقية التي تسود الأسرة مما يعطي شخصية أسرية عامة إذ إن هناك أسرة سعيدة أو أسرة قلقة أو أسرة مترابطة أو أسرة متصديدة (خليل، 2006، إسبه 16)، ويظهر ذلك من خلال درجتاه على مقياس المناخ الأسري المستخدم في الدراسة من إعداد عفراء ابراهيم خليل (2006). 


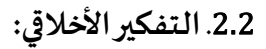

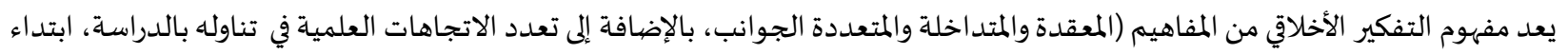

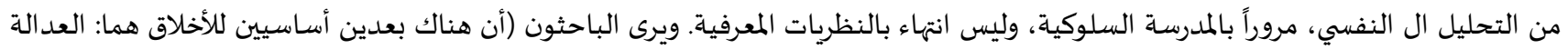

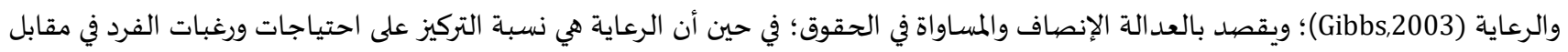
احتياجات الآخرين.

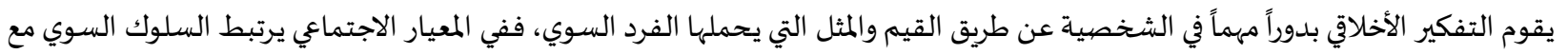

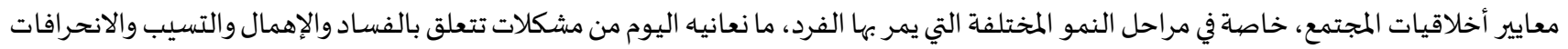

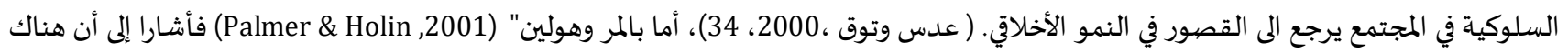

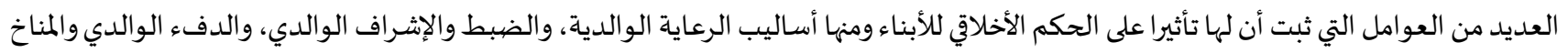
الأسري بشكل عام.

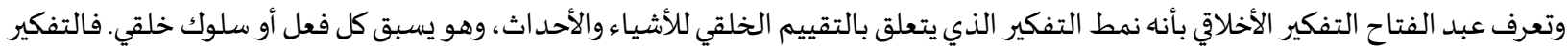

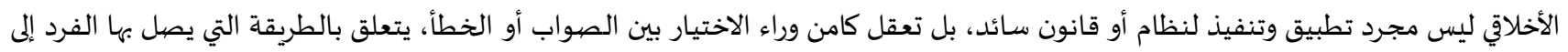

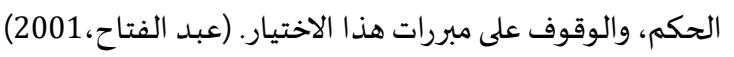
تتبنى الباحثة التعريف الاجر ائي لفوقية عبد الفتاح (2001) للتفكير الأخلاقي "بأنه نمط التفكير الذي يتعلق بالقيم التيم الخلقي للأشياء والأحداث،

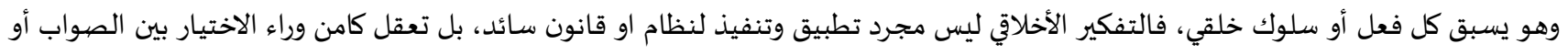

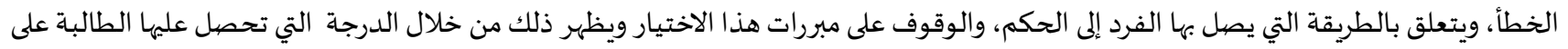
مقياس التفكير الأخلاقي المستخدم في الدراسة إعداد تامر أحمد حسن المبل (2014).

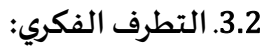

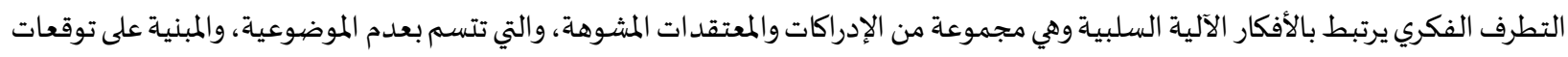

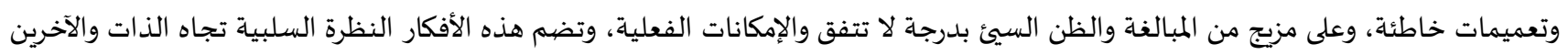

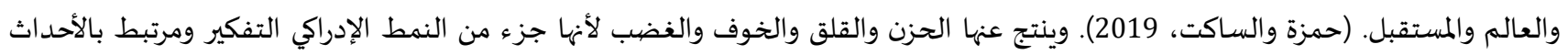

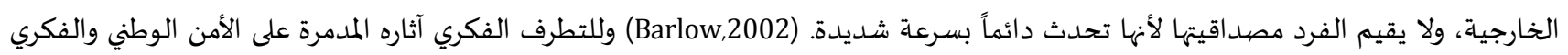

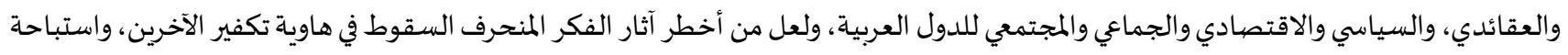

دمائهم وأموالهم. محمد الصببوة، 2013).

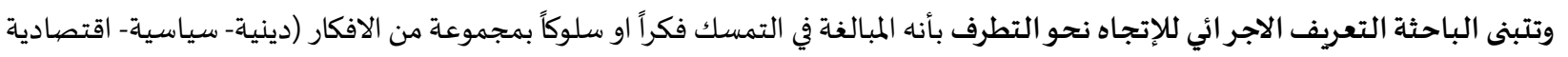

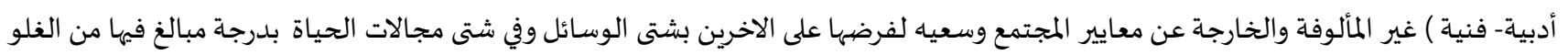

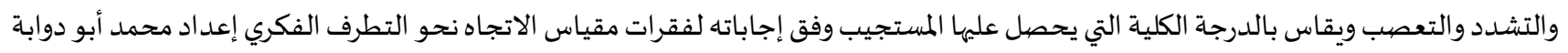

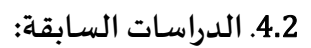

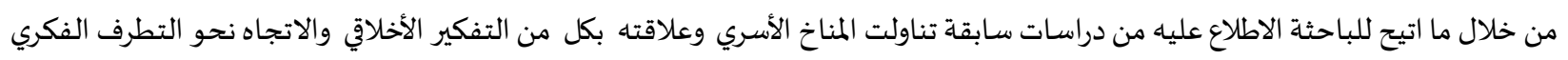
لم تجد دراسة واحدة (في حدود ما تم حصره) ربطت بين متغيرات الدراسة مجتمعة...وفيما يلي عرض الدراسات الخاصة بكات بكل متغير.

أولاً: الدراسات التي تناولت المناخ الأسري:

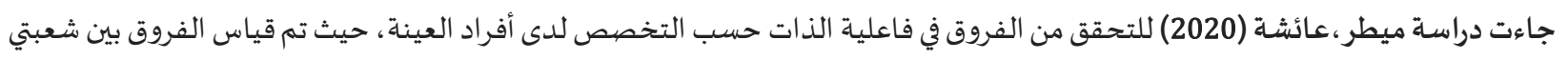

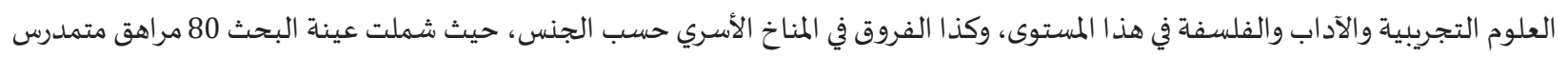

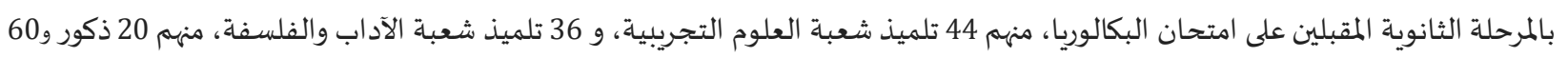

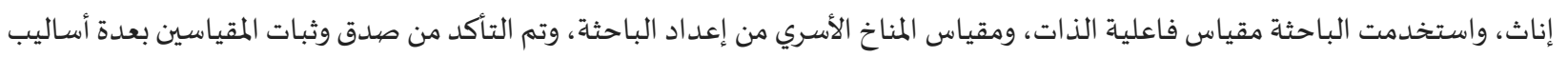

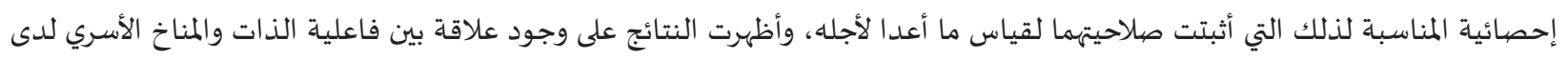

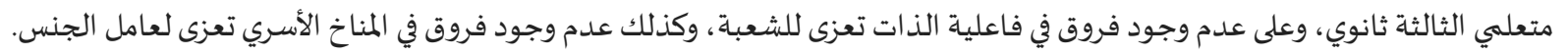

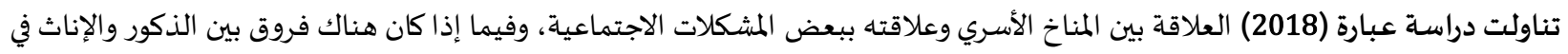

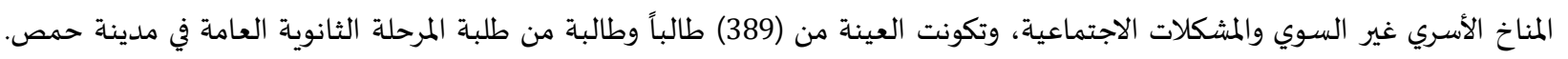


واستخدم الباحث مقياس المناخ الأسري غير السوي من إعداد ماريو رحال، ومقياس المشكلات الاجتماعية من إعداد الباحث. ومن أهم ما توصلت

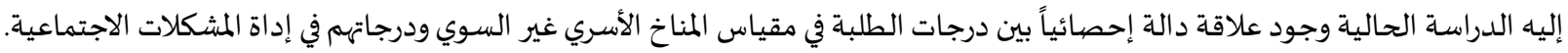
جاءت دراسـة (Mageau \& Bureau,2014) لمعرفة العلاقة بين الأساليب الوالدية في التنشئة والسلوك الأخلاقي وكانت العينة من طلاب التعليم ما

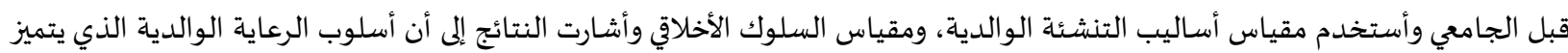

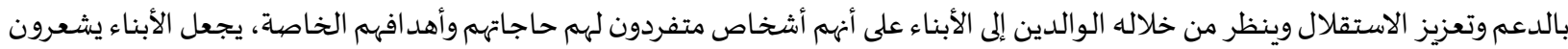

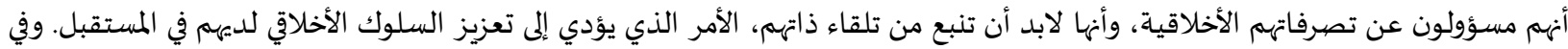

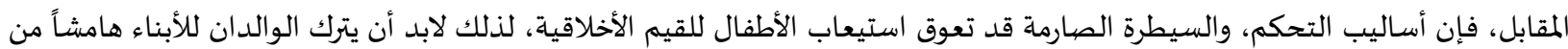
الحرية يسمح لهم بالتحكم والسيطرة في أفعالهم. كما هدفت دراسـة القاضي (2013) للكشف عن مستوى الأعراض النفسية المرضية، وعن طبيعة المناخ الأسري السائد، والعلاقة بينهما لدى

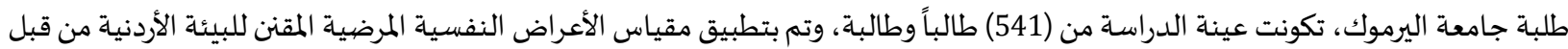
الشريفين والشريفين (2011)، ومقياس موس وموس (Moos \&Moos , 1986 ) المعد للكشف عن المناخ الأسري. أشارت أهم النتائج وجود علاقة ارتباطية سلبية بين المناخ الأسري من جهاة، والأعراض النفسية المرضية الخاصة ومة بالأبعاد التالية: الاكتئاب، والحساسية التفاعلية، والقلق، والعدوانية. أما دراسـة التاج (2012) هدفت إلى التعرف على الفروق في الحكم الخلقي بين الأفراد المعوقين والعاديين في الأردن وعلاقتها باتجاهات التنشئة الوالدية. تكونت عينة الدراسة من 237 فرداً، 167 من ذوي الإعاقات: (الحركية؛ والسمعية؛ وإلبصرية؛ ومن ذوي صعاسية صعوبات التعلم)؛ و70 من

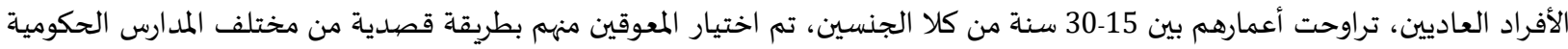

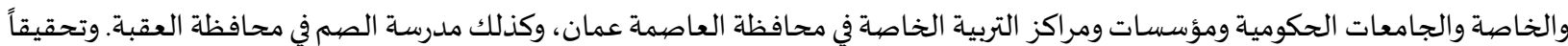
لأهداف الدراسة، تم بناء مقياسين أحدهما لقياس مستوى الحكم الخلقي، والثاني لقياس اتجاهات التنشئة الوالدياة، عند أفراد الدراسة، وقد جرى التوصل لدلالات صدق وثبات مناسبة لكلا المقياسين. وأشارت نتائج الدراسـة إلى عدم وجود فروق ذات دات دلالة إحصائية في الحكم الخلقي

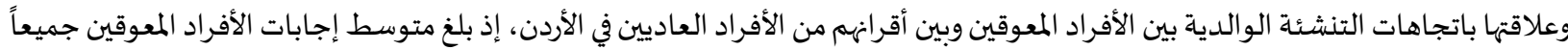

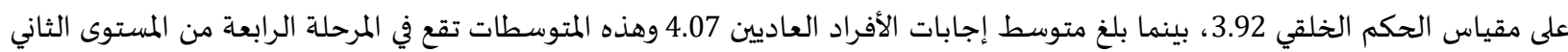
للحكم الخلقي، وأشارت معاملات الارتباط كذلك إلى وجود علاقة إيجابية دالة بين أنماط التنشئة الوالدية المتمثلة بنمط التنشئة الحزم وبين

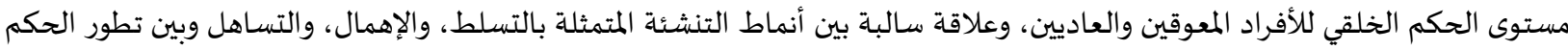
الخلقي للفئتين. بينما دراسـة (Ting, San-Rong and Guang-Sin 2011) فقد هدفت إلى الكشف عن العلاقة بين سمات الشخصية والمناخ الأسرية وكفاءة الحكم

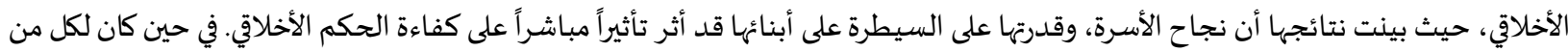
تماسك الأسرة، والوازع الأخلاقي-الديني، والتنظيم والسيطرة تأثير غير مباشر جاء من خلال أبعاد سمات الشخصية المتعلقة بالطيبة والذكاء والصدق.

ثانياً: الدراسات التي تناولت التفكير الأخلاقي:

هدفت دراسة إسماعيل، إههاب سيد (2020) إلى بناء مقياسي التفكير الأخلاقي والمسئولية الاجتماعية لدى مدربي السباحة والتعرف على العلاقة بينهما، واستخدم الباحث المنهج الوصفي باستخدام الأسلوب المستي، على عينة قوامها (200) مدرب، إسباء تم إجراء الدراسة الأسـاسية على عينة قوامها (150) مدرب، كما تم إجراء الدراسة الاستطلاعية على عينة قوامها (50) مدرب من نفس مجتمع البحث وخارج العينة الأساسية، وقد أظهرت نتائج البحث أن: • أوضحت نتائج صدق المحكرئ أدمين اتفاق الآراء حول محاور المقياس التفكير الأخلاقي (4) أبعاد والاتفاق حول محتوى العبارات (31) عبارة.

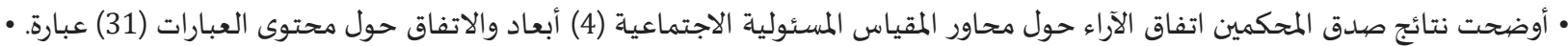

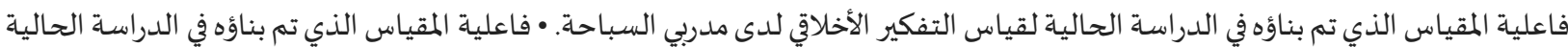
لقياس المسؤولية الاجتماعية لدى مدربي السباحة. • المحاور التي توصل إلها الباحث قادرة على قياس التفكير الأخلاقي لدى مدربي السباحة. • المحاور التي توصل إليها الباحث قادرة على قياس المسؤولية الاجتماعية لدى مدربي السباحة. أجريت دراسة قاسم (2018) للتعرف على مستوى المرونة النفسية وعلاقتها بالتفكير الأخلاقي لدى عينة قوامها (148) طالب وطالبة من كلية التربية بجامعة المجمعة بالسعودياة، وتم تقسيمههم إلى مجموعات وفقاً لبعض المتتغيرات الديموجرافية (الجنس، التخصيص المرونه الأكاديمي، سنوات الدراسة، وقامت الباحثة بتطبيق مقياس المرونة النفسية من إعدادها ومقياس التفكير الأخلاقي من إعداد فوقية عبد الفيد الفتاح (2001) وقد أشارت 
أهم نتائج الدراسة إلى وجود علاقة دالة إحصائياً بين المرونة النفسية والتفكير الأخلاقي لدى عينة الدراسـة، وتوجد فروق دالة إحصائياً بين

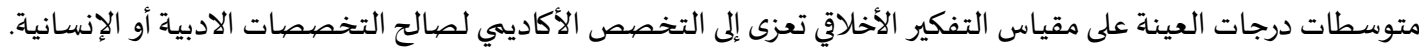
وقد أجريت دراسـة أبو نجيلة (2015) للتحقق من صحة بعض افتراضات نظرية كولبرج في التفكير الأخلاقي، وتحددت مشكلة الدراسـة في التساؤل

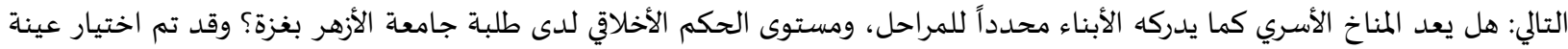

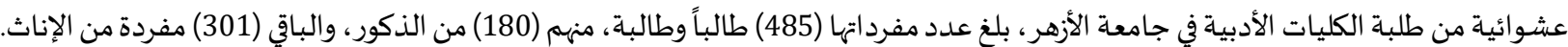
كما استخدم الباحث مقياسين، الأول مقياس المناخ الأسري من إعداد الباحث، والآخر فهو مقياس التفكير الأخلاقي للراشدين. (إعداد: فوقياة عبد

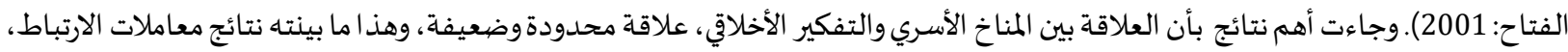
كما أن تأثير المناخ الأسري على مراحل التفكير الأخلاقي، جاءت أيضاً ضعيفة جداً، ولات تأثير ألبته له، وأن المناخ الأسري وليس التنشئة الاجتماعياعية فقط- لا علاقة له بالتفكير الأخلاقي. أما دراسة على، حامد (2012) فكان هدفها الكشف عن مدى فاعلية برنامج سلوكي يعتمد على ثلاثة استراتيجيات هي المناقشة الأخلاقية والتعليم بالنموذج ولعب الدور في تنمية التفكير الأخلاقي لدى عينة من طالبات كلية التربية، وقد شملت عينة الدراسة على (60) طالبة تم تقسيمهم إلى ثلاث

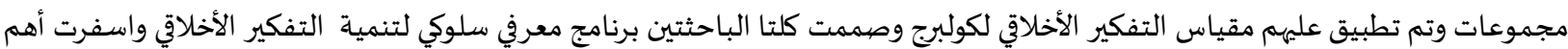

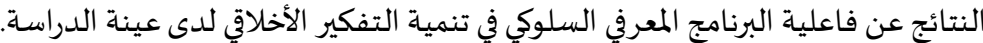
وأجرى بارك (Park, 2011) دراسـة هدفت إلى وصف العلاقة بين الحساسية الأخلاقية والتفكير الأخلاقي لطالبات التمريض، وتكونت عينة الدراسة من (146) طالبة من مدارس التمريض في كوريا الجنوبية. واستخدمت الدراسة استبياناً يتضمن البيانات الديموجرافية والحساسية الأخلاقية، واختبار مواقف التفكير الأخلاقي. وتوصلت النتائج إلى وجود علاقة ارتباطية بين كل من الحساسية الأخلاقية ومتغيرات مرتبطة بالمنهج، والتفكير الأخلاقي وخصائص الطلاب كالعمر وعدد الأخوة والجنس والدين. وفي دراسة مقدادي (2010) هدفت إلى التعرف على علاقة التفكير الخلقي بكل من الوجود النفسي الممتلئ والسلوك الاجتماعي الإيجابي لدى عينة من (237) طالباً وطالبة من طلبة البكالوريوس في كلية التربية جامعة الباحة بالمملكة العربية السعودية. منهم 98 من الذكور و 139 من الإناث اختيروا عشوائياً، واستخدم الباحث مقياس التفكير الخلقي، ومقياس الوجود النفسي الممتلئ ومقياس السلوك الاجتماعي الإيجابي. وقد أظهرت

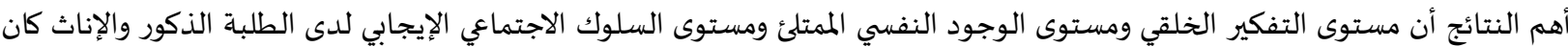

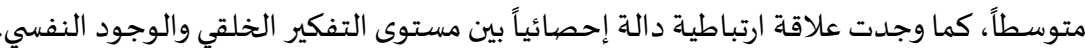

ثالثاً: الدراسات التي تناولت الاتجاه نحو التطرف الفكري: هدفت دارسة المعايطة، حمزة (2020) إلى معرفة طبيعة الإرهاب والتطرف الفكري من حيث المفهوم والدوافع وسبل المواجهة للحد منها ولوقاية

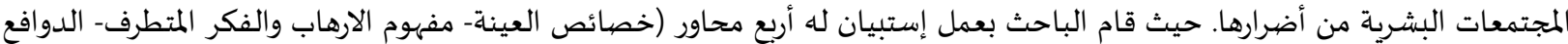

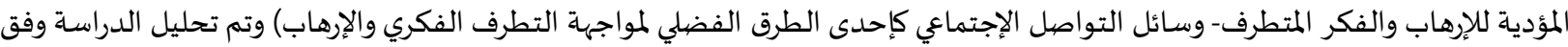

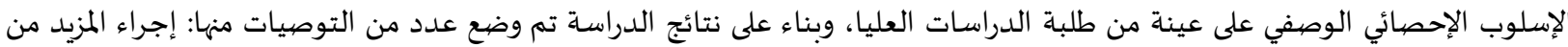
الدراسات والأبحاث العلمياة حول العوامل المؤدية للإرهاب والتطرف من قبل الباحثين والمؤسسات العلمية وأن توثق وفق إحصائيات ذات مصادر موثقه يسهل الحصول عليه من قبل الباحثين، وتوعية الأسر والمجتمع المحلي بدور المؤسسات التربوية والمؤسسات الأمنية في آلية الوقاية من الإرهاب والتطرف الفكري في المجتمع، وتوزيع الدراسة على المؤسسات المعنية في مجال الوقاية والحماية من الإرهاب والتطرف في المجتمعات البشرية. كما أجريت دراسة الخولي، متولي(2018) للتعرف على العلاقة بين التطرف الفكري لدى عينة من طلاب جامعة سطام وكل من هوية الأنا، والمرونة

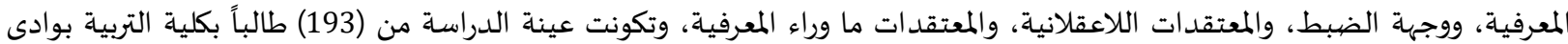

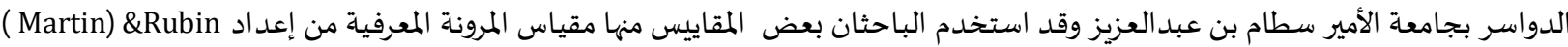
ومقياس التطرف الفكري إعداد الباحثين، (ومقياس مركز الضبط) إعداد (Davidson) .وقد توصلت أهم نتائج الدراسة إلى أن قيم معاملات

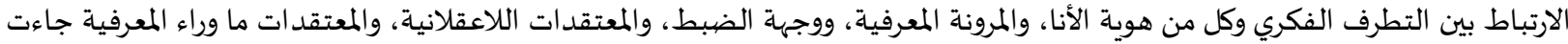

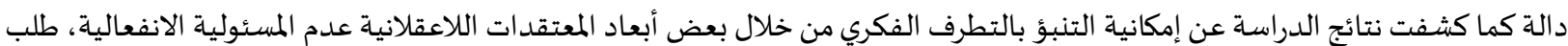
الاستحسان، الاستعلاء، (وبعض أبعاد المعتقدات ما وراء المعرفية) كما كشفت نتائج الدراسة عن إمكانية التنبؤ بالتطرف الفكري من خلال

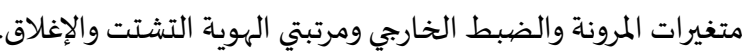
وهدفت دراسة عقيل، سلامة؛ وفرح، عبدالفتاح (2016) إلى الكشف عن مستوى المرونة المعرفية والتطرف الفكري، والعلاقة بينهما لدى عينة من طلاب جامعة الأمير سطام بن عبد العزيز ، وتكونت عينة الدراسة من (3589) طالباً وطالبة ، ولتحقيق أهد اف الدراسة قام المبله الباحثان باستخدام مقياس المرونة الذى طوره ( Dennis\&Vander,2010) بعد ترجمتاه واستخراج دلالات صيدقه وثباته، كما قام الباحثان ببناء مقياس التطرف 
الفكري، وقد أظهرت نتائج الدراسة وجود علاقة ارتباطية عكسية دالة بين المرونة المعرفية والتطرف الفكري، كما أشارت إلى وجود فروق ذات

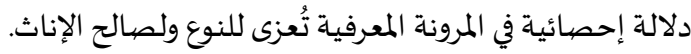

وأجريت دراسـة المدادحة (2015) للتعرف على مستوى الضغوط النفسية لدى طلبة جامعة مؤته، وعلاقتها بكل من التطرف الفكري وتقدير الذات والتحصيل الدراسي، وطبقت الدراسة على عينة قوامها (755) من الطلاب وطبق عليهم ثلاث مقاييس هي مقياس الضغوط النفسية ومقياس

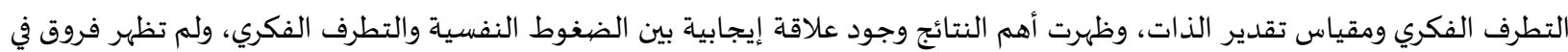
التطرف الفكري تعزى للتخصص. تعليق عام على الدراسات السابقة: من خلال الدراسات السابق عرضها والتي تناولت متغيرات الدراسة نستخلص ما يلي: إن أغلب الدراسـات اجريت على طلاب الجامعة.

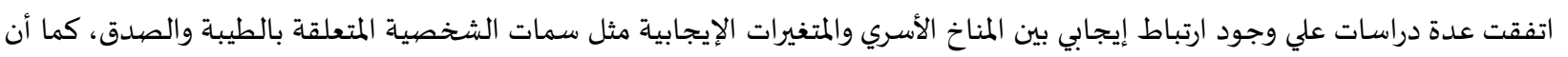
المناخ الأسري لله تأثير علي الحكم الأخلاقي (Ting, San-Rong and Guang-Sin 2011)، وتعارضت هذه النتائج مع (أبونجيلة، 2015) وكانت أهم نتائجها؛ أن العلاقة بين المناخ الأسري والتفكير الأخلاقي، علاقة محدودة الإئ وضيعيفة. وجود ارتباط بين المناخ الأسري غير السوي وبعض المتنغيرات السلبية مثل المشكلات الاجتماعية، كما أظهرت نتائج الدراسات وجود ارتباط سلبي

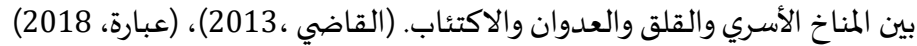
كما أظهرت بعض البحوث وجود ارتباط بين انماط التنشئة الوالدية وبعض المتغيرات، بحيث كلما كان النمط متجها نحو الحزم كان الأبناء في

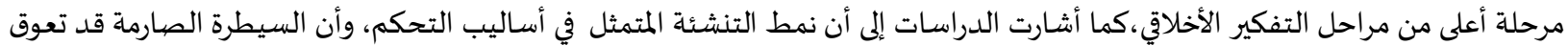

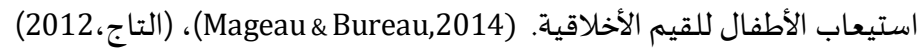
هناك عدم اتفاق إلى حداً ما في نتائج الدراسات الخاصة التي تناولت التفكير الأخلاقي حيث أظهرت بعض الدراسات وجود فروق تعزي لمتغير السن والجنس والتخصص العلمي في مستوي التفكير الأخلاقي (قاسم،2018) ، (Park,2011) في حين كانت النتائج تشير إلى أن الطلبة الذكور والإناث كان درجاتهم في المتوسط. (مقدادي ، 2010) أما عن الدراسات التي تناولت التطرف الفكري؛ فقد أكدت نتائج العديد من الدراسات علي وجود علاقة ارتباطية عكسية بين التطرف الفكري والمرونة المعرفية (الخولي، 2018) ، عقيل، سلامة؛؛(وفرح، عبدالفتاح، 2016) .

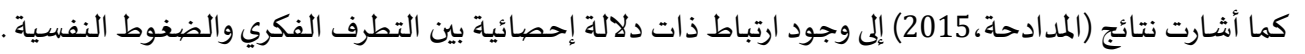

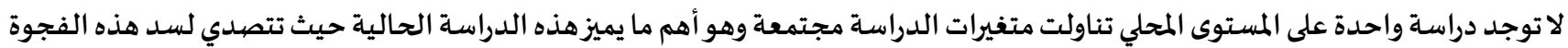

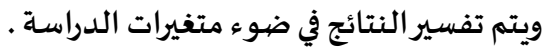
3. إجراءات الدراسة: 1.3. منهج الدراسـة: نظراً لان المهدف من الدراسة هو التعرف على المناخ الأسري كمتغير وسيط في العلاقة بين التفكير الأخلاقي والاتجاه نحو التطرف الفكري فإن المنهج المناسب هو المنهج الوصفي الطريقة الارتباطية والمقارنة.

هو الطالبات بجامعة الملك خالد بأبها (بكلياتها العلمية والأدبية).

تم اختيار عينة عرضية وهي العينة المتاحة بالنسبة للباحثة -وتتم من خلال موافقة أفراد العينة على تطبيق المقاييس- من الطالبات قوامها (250)

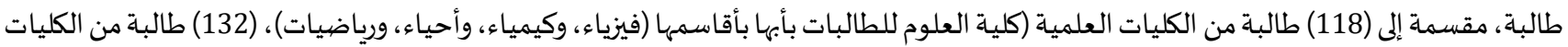

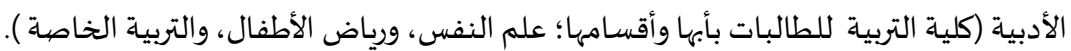

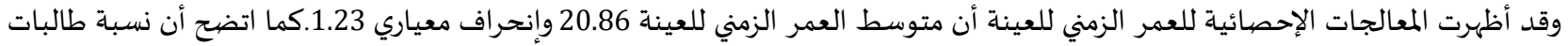

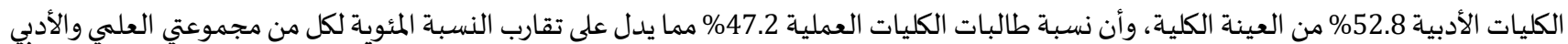
في عينة الدراسة. 


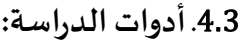

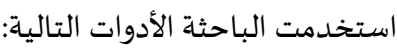

أولاً: مقياس المناخ الأسري: إعداد عفراء ابراهيم خليل (2006).

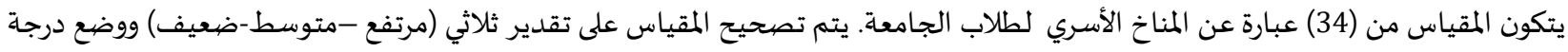

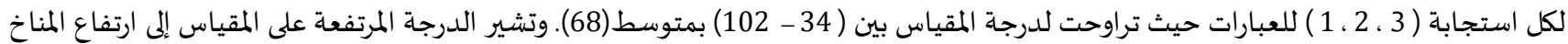

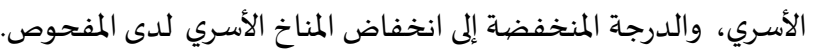

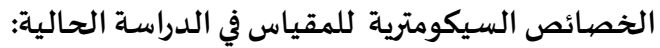
قامت الباحثة بتطبيق مقياس المناخ الأسري على عينة استطلاعية مكونة من (50) من طالبات جامعة الملك خالد، وذلك لحساب صيدة لحقد وثبات أدوات

قامت الباحثة بالتأكد من صدق المقياس المقياس من خلال استخدام صددقالاتساق الداخلي: تم حساب معامل الارتباط بين درجة كل عبارة وبالدرجة الكلية

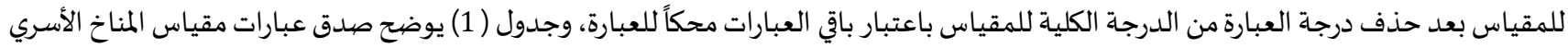
لطلاب الجامعة جدول (1): صدق الاتساق الداخلي لمفردات مقياس المناخ الأسري لطالبات جامعة الملك خالد

\begin{tabular}{|c|c|c|c|c|c|}
\hline معامل الارتباط بالدرجة & رقم العبارة & بالدرجة الكلية & رقم العبارة & معامل الارتباط بالدرجة & رقم العبارة \\
\hline$* * 0.620$ & 25 & $* * 0.629$ & 13 & $* * 0.730$ & 1 \\
\hline$* * 0.681$ & 26 & $* * 0.687$ & 14 & ${ }^{* *} 0.835$ & 2 \\
\hline$* * 0.766$ & 27 & **0.785 & 15 & $* * 0.723$ & 3 \\
\hline$* * 0.748$ & 28 & $* * 0.761$ & 16 & $* * 0.743$ & 4 \\
\hline$* * 0.506$ & 29 & $* * 0.489$ & 17 & ${ }^{* *} 0.771$ & 5 \\
\hline${ }^{* *} 0.473$ & 30 & **0.492 & 18 & ${ }^{* *} 0.569$ & 6 \\
\hline$* * 0.772$ & 31 & $* * 0.787$ & 19 & ${ }^{* *} 0.752$ & 7 \\
\hline${ }^{* *} 0.547$ & 32 & $* 0.538$ & 20 & $* * 0.578$ & 8 \\
\hline$* * 0.742$ & 33 & $* * 0.726$ & 21 & **0.693 & 9 \\
\hline \multirow[t]{3}{*}{${ }^{* *} 0.684$} & 34 & $* * 0.737$ & 22 & **0.617 & 10 \\
\hline & & $* * 0.518$ & 23 & $* * 0.503$ & 11 \\
\hline & & $* * 0.504$ & 24 & ${ }^{* *} 0.597$ & 12 \\
\hline
\end{tabular}

* تعنى أن العبارة دالة إحصائياً عند مستوى 0.097 ** تعنى أن العبارة دالة إحصبائياً عند مستوى 0.01 قيمة "ر" الجدولية عند مستوى دلالة 0.05 قيمة "ر" الجدولية عند مستوى دلالة 0.01 يتضح من الجدول أن جميع عبارات مقياس المناخ الأسري لها علاقة ارتباطية ذات دلالة دالة احصائية بالدرجة الكلية للمقياس. مما يشير أن المقياس يتمتع بدرجة عالية من الاتساق الداخلي تسمح باستخدامها.

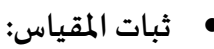

قامت الباحثة بحساب الثبات لمقياس المناخ الأسري باستخدام معامل ألفا كرونباخ، والتجزئة النصفية بطريقة سبيرمان براون والجدول (2) يوضح

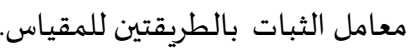
جدول (2): معاملات ثبات مقياس المناخ الأسري

\begin{tabular}{|c|c|c|c|}
\hline الثبات بطريقة ألفا كرونباخ & الثبات بطريقة التجزئة النصفية & عدد العبارات & المقياس \\
\hline 0.960 & 0.945 & 34 & المناخ الأسري \\
\hline
\end{tabular}

يتبين من الجدول أن مقياس المناخ الأسري يتمتع بدرجات مرتفعة من الثبات مما يشير إلى الوثوق بنتائج المقياس.

ثانياً: مقياس التفكير الأخلاقي: إعداد تامر أحمد حسن (2014).

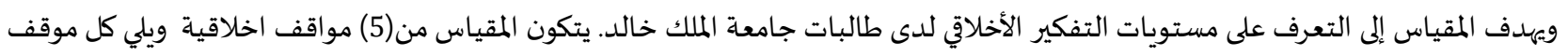
عدد من الاسئلة على الطالب ان يختار الاجابة المناسبة له من ضمن ستأة اختيارات. يتم تصحيح المقياس على تقدير خماسي ووضع درجة لكل الكل استجابة ( 6، 5 ، 4، 3 ، 2 ، 1) للعبارات حيث الاسلى تراوحت لدرجة المقياس بين (21 - 126) وتشير الدرجة المرتفعة على المقياس إلى ارتفاع التفكير الأخلاقي، والدرجة

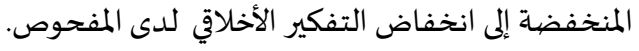
الخصائص السيكومترية للمقياس في الدراسة الحالية: قامت الباحثة بتطبيق مقياس التفكير الأخلاقي على عينة استطلاعية مكونة من (50) من طالبات جامعة الملك خالد، وذلك لحساب صدئ لدق وثبات 
• الصدق قامت الباحثة بالتأكد من صهدق المقياس من خلال الاتساق الداخلي:

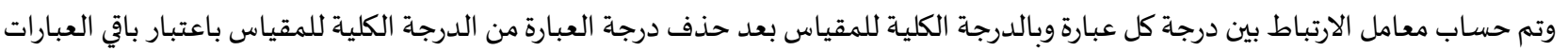

محكاً للعبارة، وجدول (3) يوضح صددق عبارات مقياس التفكير الأخلاقي لطالبات الجامعة .

\begin{tabular}{|c|c|c|c|c|c|}
\hline معامل الارتباط بالدرجة & رقم العبارة & بالدرجة الكلية & رقم العبارة & معامل الارتباط بالدرجة & رقم العبارة \\
\hline$* * 0.541$ & 15 & $* * 0.797$ & 8 & $* * 0.565$ & 1 \\
\hline${ }^{* *} 0.673$ & 16 & $* * 0.791$ & 9 & $* * 581$ & 2 \\
\hline${ }^{* *} 0.640$ & 17 & ${ }^{* *} 0.418$ & 10 & ${ }^{* *} 0.547$ & 3 \\
\hline${ }^{* *} 0.470$ & 18 & ${ }^{* *} 0.626$ & 11 & ${ }^{* *} 0.614$ & 4 \\
\hline${ }^{* *} 0.582$ & 19 & $* * 0.557$ & 12 & ${ }^{* *} 0.749$ & 5 \\
\hline${ }^{* *} 0.703$ & 20 & $* * 0.524$ & 13 & $* * 0.584$ & 6 \\
\hline${ }^{* *} 0.789$ & 21 & ${ }^{* *} 0.522$ & 14 & ${ }^{* *} 0.793$ & 7 \\
\hline
\end{tabular}

* تعنى أن العبارة دالة إحصائياً عند مستوى 0.05 * * تعنى أن العبارة دالة إحصائياً عند مستوى 0.01 قيمة "ر" الجدولية عند مستوى دلالة 0.05 قيمة "ر" الجدولية عند

مستوى دلالة 0.01

يتضح من الجدول أن كل عبارات مقياس التفكير الأخلاقي لها علاقة ارتباطية ذات دلالة إحصائية بالدرجة الكلية للمقياس. مما يعنى أن المقياس يتمتع بلدرجة عالية من الاتساق الداخلي مما يسمح باستخد امها. ثبات المقياس:

قامت الباحثة بحساب الثبات باستخدام معامل ألفا كرونباخ، والتجزئة النصفية بطريقة سبيرمان براون والجدول (4) يوضح معامل الثبات بالطريقتين للمقياس. جدول (4)معاملات ثبات مقياس التفكير الأخلاقي

\begin{tabular}{|c|c|c|c|}
\hline الثبات بطريقة ألفا كرونباخ & الثبات بطريقة التجزئة النصفية & عدد العبارات & المقياس \\
\hline 0.910 & 0.884 & 21 & التفكير الأخلاقي \\
\hline
\end{tabular}

يتبين من الجدول أن مقياس التفكير الأخلاقي يتمتع بدرجات مرتفعة من الثبات مما يشير إلى الوثوق بنتائج المقياس.

ثالثاً: مقياس الاتجاه نحو التطرف الفكري:إعداد محمد أبودو ابة (2012)

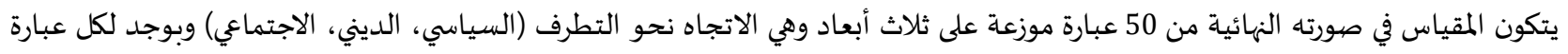

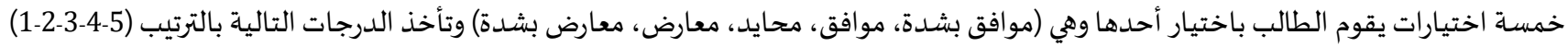
ويتم تصحيح وتجميع درجات الطالب وهي تمثل الدرجة الكلية على المقياس ويشير ارتفاع درجات الطالب بانها يتسم باتجاهات متطرفة في استجاباته

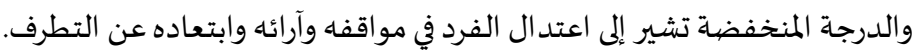
الخصبائص السيكومترية لمقياس الاتجاه نحو التطرف الفكري: • • قامت الباحثة بحساب ثبات مقياس الاتجاه نحو التطرف الفكري باستخدام كل من طريقة ألفاكرونباخ، و جتمان، على عينة قوامها (ن=50) من الطالبات، وقد جاءت النتائج كما يوضحها الجدول التالي: جدول (5): معاملات الثبات بطريقة جتمان و ألفاكرونباخ لمقياس الاتجاه نحو التطرف الفكري

\begin{tabular}{|c|c|c|c|}
\hline معامل الثبات ألفا كرونباخ & معامل الثبات بطريقة جتمان & عدد العبارات & الأبعادوالدرجة الكلية \\
\hline 0.956 & 0.945 & 16 & الاتجاه نحو التطرف الديني \\
\hline 0.841 & 0.864 & 16 & الاتجاه نحو التطرف السياسي \\
\hline 0.961 & 0.934 & 18 & الاتجاه نحو التطرف الاجتماعي \\
\hline 0.942 & 0.936 & 50 & الدرجة الكلية للمقياس \\
\hline
\end{tabular}

يتضح من الجدول أن معاملات الثبات لمقياس الاتجاه نحو التطرف الفكري جميعها معقولة وذلك لجميع أبعاد المقياس، وكذلك الدرجة الكلية،

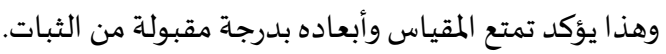


قامت الباحثة بالتحقق من صيدق مقياس عن طريق صداق الاتساق الداخلي على عينة قوامها (ن = 50) من طالبات جامعة الملك خالد بجده وذلك

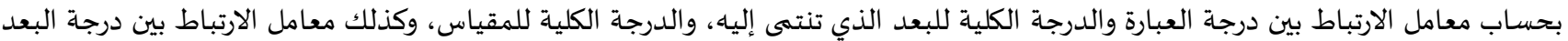
والدرجة الكلية للمقياس، وفيما يلى جدول (6) يوضح معاملات الارتباط بين درجة كل عبارة من عبارات الأبعاد الستة والدرجة الكلية للبعد.

\begin{tabular}{|c|c|c|c|c|c|}
\hline 2 & 1) & م & 2 & 1) & م \\
\hline${ }^{* *} 0.789$ & ${ }^{* *} 0.758$ & 26 & $* * 0.836$ & $* 0.830$ & 1 \\
\hline${ }^{* *} 0.700$ & ${ }^{* *} 0.689$ & 27 & $* 0.829$ & ${ }^{* *} 0.840$ & 2 \\
\hline${ }^{* *} 0.800$ & ${ }^{* *} 0.735$ & 28 & $* * 0.705$ & $* 0.668$ & 3 \\
\hline${ }^{* *} 0.843$ & ${ }^{* *} 0.847$ & 29 & ${ }^{* *} 0.821$ & $* 0.818$ & 4 \\
\hline$* * 0.695$ & $* * 0.711$ & 30 & $* * 0.745$ & ${ }^{* *} 0.695$ & 5 \\
\hline **0.810 & $* * 0.854$ & 31 & ${ }^{* *} 0.789$ & $* 0.794$ & 6 \\
\hline **0.689 & **0.718 & 32 & ${ }^{* *} 0.698$ & $* * 0.713$ & 7 \\
\hline$* * 0.782$ & $* * 0.778$ & 33 & ${ }^{*} 0.789$ & $* 0.803$ & 8 \\
\hline${ }^{* *} 0.689$ & ${ }^{* *} 0.635$ & 34 & ${ }^{* *} 0.812$ & $* 0.795$ & 9 \\
\hline$* * 0.759$ & $* * 0.778$ & 35 & $* * 0.701$ & ${ }^{* *} 0.671$ & 10 \\
\hline **0.793 & ${ }^{* *} 0.815$ & 36 & ${ }^{* *} 0.822$ & $* 0.841$ & 11 \\
\hline **0.758 & $* * 0.715$ & 37 & ${ }^{*} 0.839$ & $* * 0.872$ & 12 \\
\hline **0.859 & $* * 0.832$ & 38 & ${ }^{* *} 0.668$ & $* 0.664$ & 13 \\
\hline$* * 0.846$ & ${ }^{* *} 0.856$ & 39 & $* * 0.815$ & $* * 0.757$ & 14 \\
\hline$* * 0.708$ & $* * 0.721$ & 40 & ${ }^{* *} 0.694$ & ${ }^{* * 0} 0.658$ & 15 \\
\hline **0.859 & $* * 0.835$ & 41 & $* * 0.748$ & $* 0.735$ & 16 \\
\hline$* * 0.714$ & $* * 0.715$ & 42 & ${ }^{* *} 0.676$ & ${ }^{* * 0} 0.685$ & 17 \\
\hline **0.811 & $* * 0.822$ & 43 & ${ }^{* *} 0.755$ & $* * 0.683$ & 18 \\
\hline$* * 0.758$ & $* * 0.745$ & 44 & ${ }^{* *} 0.782$ & ${ }^{* * 0} 0.744$ & 19 \\
\hline **0.824 & **0.793 & 45 & ${ }^{* *} 0.711$ & ${ }^{* * 0} 0.712$ & 20 \\
\hline$* * 0.853$ & $* * 0.856$ & 46 & ${ }^{* *} 0.800$ & ${ }^{* * 0} 0.836$ & 21 \\
\hline$* * 0.847$ & $* * 0.745$ & 47 & ${ }^{* *} 0.849$ & ${ }^{* * 0} 0.821$ & 22 \\
\hline$* * 0.758$ & $* * 0.847$ & 48 & ${ }^{* *} 0.669$ & ${ }^{* *} 0.729$ & 23 \\
\hline$* * 0.789$ & $* * 0.759$ & 49 & $* * 0.797$ & ${ }^{* *} 0.808$ & 24 \\
\hline$* * 0.758$ & $* * 0.778$ & 50 & $* * 0.699$ & $* * 0.745$ & 25 \\
\hline
\end{tabular}

ويتضح أن معاملات الارتباط بين درجة كل عبارة بدرجة البعد الذى ينتمى إليه وبالدرجة الكلية للمقياس دالة إحصائياً عند مستوى (0.01)، وهو ما يشير إلى مستوى مرتفع من صدق الاتساق الد اخلي لعبارات المقياس. إجراءات التطبيق: تم التطبيق الأدوات على عينة البحث عن طريق النت من خلال إرسال رابط للمقاييس.

5.3 الأساليب الإحصيائية: استخدمت الباحثة الأساليب التالية للتحقق من صحة فروض البحث من خلال برنامج الإحصياء SPSS.V21 وهي:

$$
\begin{aligned}
& \text { المتوسطات والنسب المئوية والانحرافات المعيارية. } \\
& \text { معامل ارتباط الرتب لبيرسون. } \\
& \text { اختبار "ت" للمقارنة بين متوسطي مجموعتين مستقلتين. } \\
& \text { تحليل الانحدار الخطي للتعرف على مساهمة (المناخ الأسري والتفكير الأخلاقي) بالتنبؤ بالمتغير التابع (بالاتجاه نحو التطرف الفكري). }
\end{aligned}
$$

\begin{tabular}{|c|c|c|c|c|c|}
\hline المستوى & المنوال & الوسيط & اللمتوسبة المئوية & المتوسط الحسابي & المتغير \\
\hline مرتفع & 73.00 & 108.00 & $\% 82.52$ & 103.97 & التفكير الأخلاقي \\
\hline
\end{tabular}

1.4. نتائج التسـاؤل الأول: والذي ينص على" ما مستوى التفكير الأخلاقي لدى طالبات جامعة الملك خالد" ؟

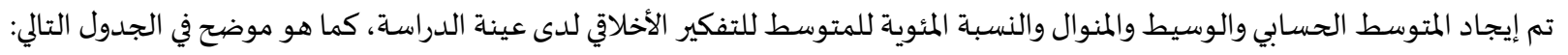
جدول (7): المتوسط الحسابي والوسيط والمنوال والنسبة للتفكير الأخلاقي لدى طالبات جامعة الملك خالد عينة الدراسة 
يتضح من الجدول السـابق أن متوسط التفكير الأخلاقي لدى طالبات جامعة الملك خالد بلغ (103.97) وبنسبة مئوية (82.52\%) وهذا يشير إلى أن مستوى التفكير الأخلاقي مرتفع لدى طالبات جامعة الملك خالد. وقد اتفقت نتيجة هذا الدراسة مع نتائج دراسة قاسم (2018) التي اشارت إلى أن طائ طالبات الجامعة يرتفع لديهم مستوى التفكير الأخلاقي ويمكن تفسير هذه النتيجة إلى أن التزام الطالبات بالمعايير الأخلاقية والأخلاق العامة وبالعادات والتقاليد

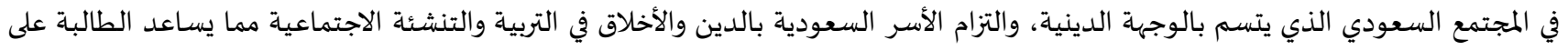
التمسك بالقيم الأخلاقية التي تساعدها في الأحكام الأخلاقية التي ترجع إلى مستوى مرتفع من التفكير الأخلاقي.

2.4. نتائج التسـاؤل الثاني الذي ينص على " ما مستوى الاتجاه نحو التطرف الفكري لدى عينة الدراسـة"؟ تم إيجاد المتوسط الحسابي والوسيط والمنوال والنسبة المئوية للمتوسط للاتجاه نحو التطرف الفكري لدى عينة الدراسـة كما هو موضح في الجدول التالي: جدول (8): المتوسط الحسابي والوسيط والمنوال والنسبة المئوية للاتجاه نحو التطرف الفكري لدى عينة الدراسة

\begin{tabular}{|c|c|c|c|c|c|c|}
\hline المستوى & المنوال & الوسيط & اللمتوسطة المئوية & المتوسط الحسابي & الأبعاد & م \\
\hline متوسط & 55.00 & 54.00 & $\% 65.68$ & 52.55 & الاتجاه نحو التطرف الديني & 1 \\
\hline متوسط & 59.00 & 54.00 & $\% 65.32$ & 52.26 & الاتجاه نحو التطرف & 2 \\
\hline متوسط & 55.00 & 54.00 & $\% 57.22$ & 51.50 & الاتجاه نحو التطرف & 3 \\
\hline متوسط & 177.00 & 163.00 & $\% 62.48$ & 156.21 & الاتجاه نحو التطرف الفكري & \\
\hline
\end{tabular}

يتضح من الجدول السابق أن مستوى الاتجاه نحو التطرف الفكري متوسط لدى عينة الدراسة ولعل هذه النتيجة تتفق مع ما توصلت إليه دراسة

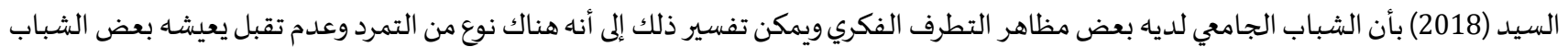
الجامعي ليس في الجامعة فقط وإنما في جميع جوانب حياتهم، ونتيجة لذلك يندفع الشباب قليلاً إلى الفكر المتطرف. 3.4. نتائج الفرض الأول الذى ينص على " توجد علاقة ارتباطية دالة إحصيائياً بين التفكير الأخلاقي و الاتجاه نحو التطرف الفكري لدى عينة الدراسة وللتحقق من صحة هذا الفرض تم حساب معاملات الارتباط بين متغيرات الدراسة "التفكير الأخلاقي، والاتجاه نحو التطرف الفكري، لدى عينة الدراسـة.

جدول (9): معاملات الارتباط بين التفكير الأخلاقي والاتجاه نحو التطرف الفكري (ن=250)

\begin{tabular}{|c|c|c|}
\hline مستوى الدلالة & معامل الارتباط بالدرجة الكلية & أبعاد الاتجاه نحو اتطرف الفكري \\
\hline 0.01 & $0.711-$ & الاتجاه نحو التطرف الديني \\
\hline 0.01 & 0.715 & الاتجاه نحو التطرف السياسي \\
\hline 0.01 & $0.820-$ & الاتجاه نحو التطرف الاجتماعي \\
\hline 0.01 & 0.759 & الدرجة الكلية \\
\hline
\end{tabular}

( قيمة رالجدولية عند مستوى دلالة $0.05=0.138$ ومستوى دلالة $0.01=0$.

يتضح من نتائج الجدول ما يلي -وجود معامل ارتباط سالب ودال إحصائياً عند مستوى دلالة (0.01) بين التفكير الأخلاقي وأبعاد الاتجاه نحو

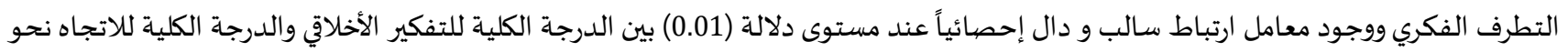
التطرف الفكري لدى عينة الدراسـة. مما يعنى أنه كلما ارتفع مستوى التفكير الأخلاقي انخفض الاتجاه نحو التطرف الفكري ولعل هذه النتيجة منطقية

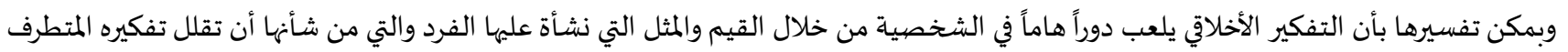

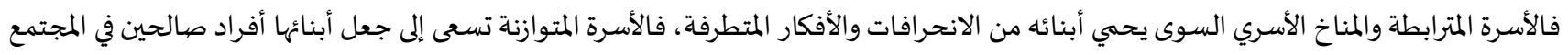

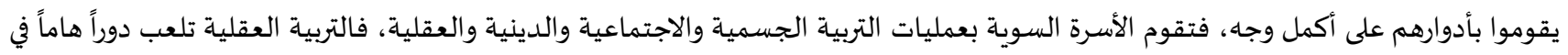
تعلم الأفراد كيف يعيشون حياة متوافقة مع القيم والأخلاقيات السائدة في المجتمع مما يقلل من الاتجاه إلى الأفكار السلبية المتطرفة. 4.4. نتائج الفرض الثاني الذي ينص على: توجد علاقة ارتباطية دالة إحصائياً بين التفكير الأخلاقي والمناخ الأسري لدى عينة الدراسـة.

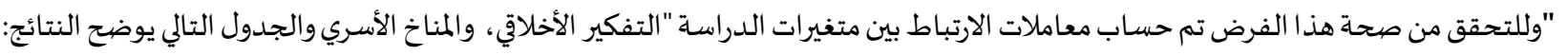




\begin{tabular}{|c|c|c|}
\hline مستوى الدلالة & معامل الارتباط بالدرجة الكلية & المناخ الأسري \\
\hline 0.01 & 0.917 & الدرجة الكلية للاتجاه نحو التطرف الفكري \\
\hline
\end{tabular}

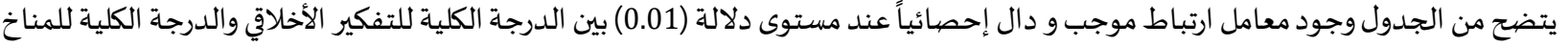

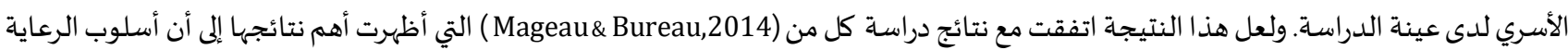

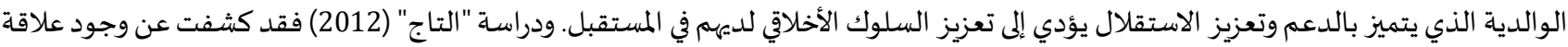

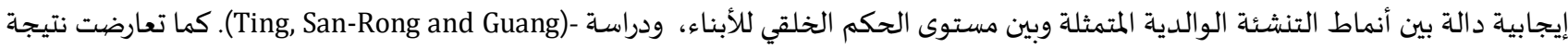

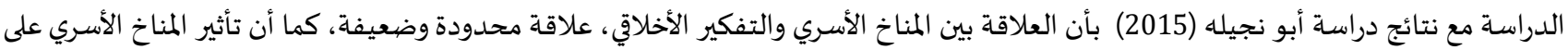

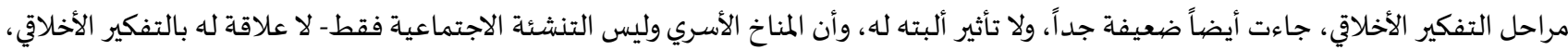

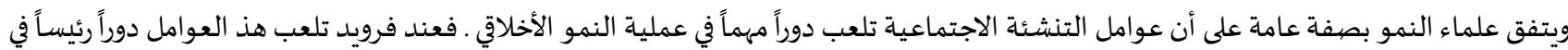

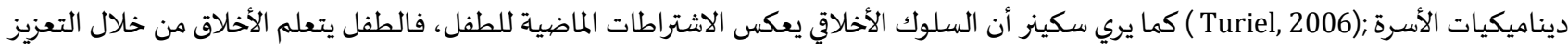

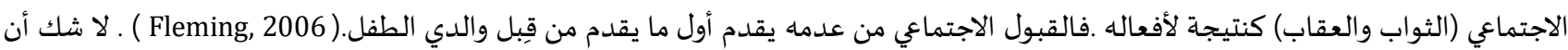

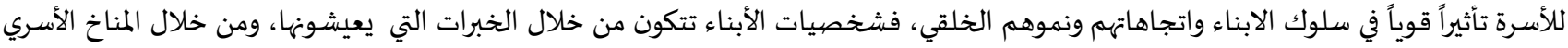

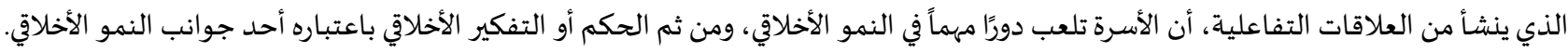
5.4 نتائج الفرض الثالث الذى ينص على "توجد فروق دالة احصائيا بين طالبات الجامعة على مقياس التفكير الأخلاقي والمناخ الأسري و الاتجاه نحو

$$
\text { التطرف الفكري تعزى لمتغير التخصص (علمي - أدبي). }
$$

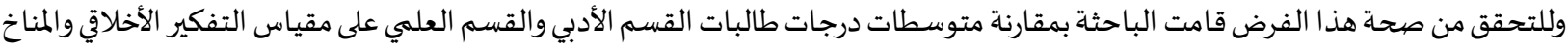

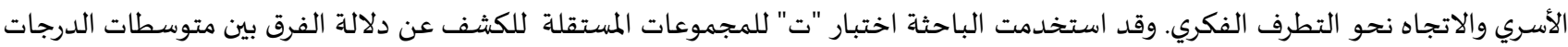
(باستخدام برنامج SPS.v21) ويوضح الجدول التالي تلك النتائج:

\begin{tabular}{|c|c|c|c|c|c|c|c|c|}
\hline \multicolumn{9}{|c|}{ الفكري } \\
\hline \multirow[t]{2}{*}{ القرار } & مستوى & قيمة ت & درجات الحرية & الانحراف & المتوسط & العدد & المجموعة & المقياس \\
\hline & \multicolumn{3}{|l|}{ الدلالة } & \multicolumn{5}{|l|}{ المعياري } \\
\hline \multirow{2}{*}{ غير دالة } & \multirow[t]{2}{*}{0.36} & \multirow[t]{2}{*}{0.92} & \multirow[t]{2}{*}{248} & $\begin{array}{l}17.82 \\
\end{array}$ & 104.98 & 132 & الأدبي & \multirow{2}{*}{ التفكير الأخلاقي } \\
\hline & & & & 18.99 & 102.84 & 118 & العلني & \\
\hline \multirow[t]{2}{*}{ غير دالة } & \multirow[t]{2}{*}{0.40} & \multirow[t]{2}{*}{0.84} & \multirow[t]{2}{*}{248} & 13.79 & 84.73 & 132 & الأدبي & \multirow[t]{2}{*}{ المناخ الأسري } \\
\hline & & & & 14.54 & 83.22 & 118 & العلمي & \\
\hline \multirow[t]{2}{*}{ غير دالة } & \multirow[t]{2}{*}{0.81} & \multirow[t]{2}{*}{0.22} & \multirow[t]{2}{*}{248} & 6.85 & 52.45 & 132 & الأدبي & \multirow{2}{*}{ التطرف الديني } \\
\hline & & & & 7.41 & 52.66 & 118 & العلهي & \\
\hline \multirow{2}{*}{ غير دالة } & \multirow{2}{*}{0.79} & \multirow{2}{*}{0.26} & \multirow{2}{*}{248} & 6.82 & 52.15 & 132 & الأدبي & \multirow{2}{*}{ التطرف السياسي } \\
\hline & & & & 6.94 & 52.38 & 118 & العلمي & \\
\hline \multirow[t]{2}{*}{ غير دالة } & \multirow[t]{2}{*}{0.56} & \multirow[t]{2}{*}{0.57} & \multirow[t]{2}{*}{248} & 8.58 & 51.21 & 132 & الأدبي & \multirow[t]{2}{*}{ التطرف الاجتماعي } \\
\hline & & & & 8.79 & 51.83 & 118 & العلمي & \\
\hline \multirow[t]{2}{*}{ غيردالة } & \multirow[t]{2}{*}{0.65} & \multirow[t]{2}{*}{0.44} & \multirow[t]{2}{*}{248} & 22.63 & 155.60 & 132 & الأدبي & \multirow[t]{2}{*}{ الدرجة الكلية } \\
\hline & & & & 22.70 & 156.88 & 118 & العلىى & \\
\hline
\end{tabular}

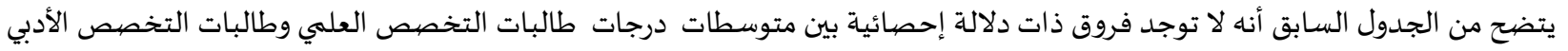

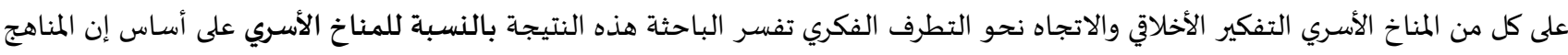

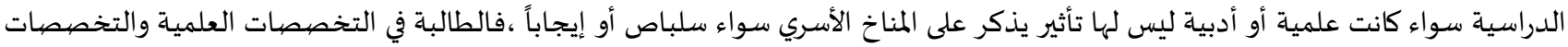

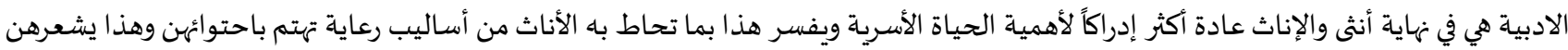

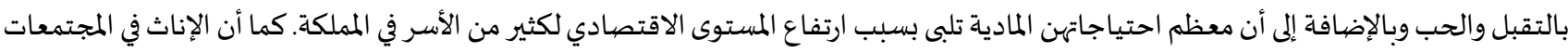

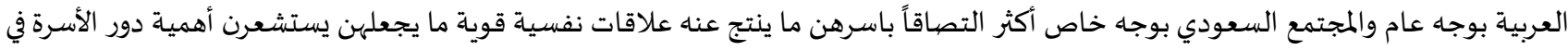

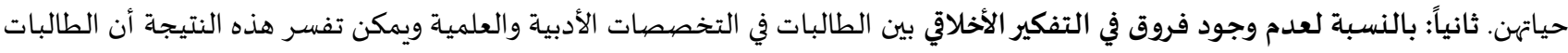
بشكل عام سواء من التخصصيات الأدبية أو التخصصيات العلمية هن أبناء المجتمع السعودي ويعيشن في المجتمع نفسه الذي يتميز بالالتزام والتمسك التك بالعادات والتقاليد وتنشئة أبنائها على أسـاس ديني وأخلاقي مما يساعد الطالبة على التمسك بالقيم الأخلاقية التي تساعدها في الأحكام الأخلاقية التي 
ترجع إلى مستوى مرتفع من التفكير الأخلاقي. ويمكن تفسر هذه النتيجة أيضاً إلى أن المقررات سواء كانت أدبية أو علمية توجد بها مواد إجبارية لجميع

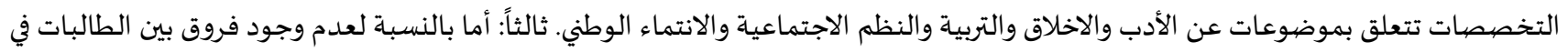
الاتجاه نحو التطرف الفكري تعزى للتخصص وقد كان مستوى الاتجاه نحو التطرف الفكري لديهن متوسط فيمكن تفسير ذلك أن الشباب بشكل عام

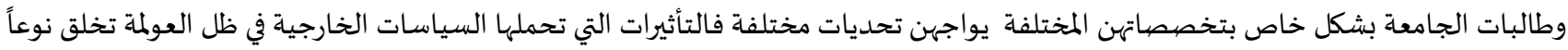

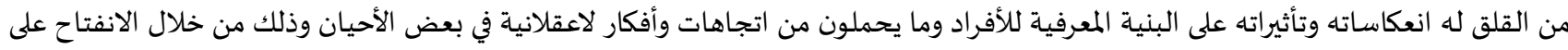

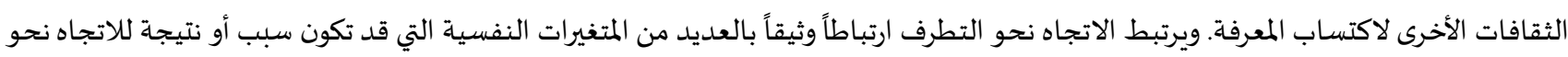

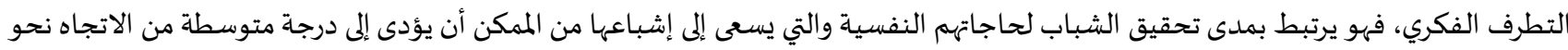
التطرف الفكري.

6.4. نتائج الفرض الر ابع الذى ينص على " من المتوقع أن يتغير حجم الارتباط لدى أفراد عينة الدراسـة بين التفكير الأخلاقي والاتجاه نحو التطرف

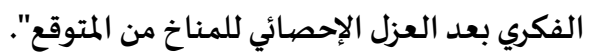
للتحقق من صحة هذا الفرض استخدم معامل الارتباط الجزئي لحساب العلاقة بين الاتجاه نحو التطرف والتفكير الأخلاقي بعد العزل الإحصائي

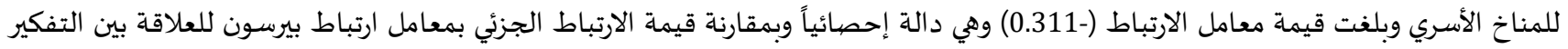

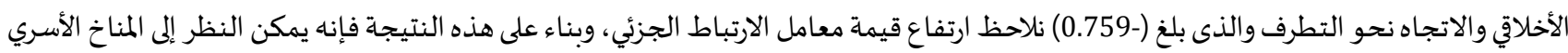
بوصفاه متغير وسيط العلاقة بين التفكير الأخلاقي والاتجاه نحو التطرف، ومن ثم يمكن التنبؤ بأنه في ظل غياب المناخ الأسري يمكن أن أن تنشط التهاء الآثار

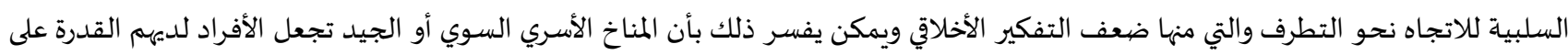

التمسك بالقيم الخاصة وعدم السماح للمتغيرات الناجمة عن الانحرافات الأخلاقية .

: 7.4 التوصيات:

في ضوء النتائج التي توصلت إليها هذه الدراسة فإنها يمكن تقديم التوصيات الآتية:

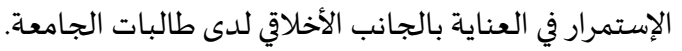

العمل على تقديم برامج إرشادية عن ماهية الاتجاه نحو التطرف الفكري.

تعزيز التربية الأخلاقية والوطنية لدى طالبات الجامعة.

العمل على تقديم برامج إرشادية للوصول بكفاءة التفكير الأخلاقي لدى طلاب الجامعة لأعلى المستويات.

8.4 المقترحات:

التفكير الأخلاقي لدى عينات مختلفة من المجتمع السعودي.

فاعلية برنامج إرشادي جمعي لخفض الاتجاهات المتطرفة لدى طالبات الجامعة.

المناخ الأسري وعلاقتاه بالتفكير الأخلاقي لدى عين من طلاب (الذكور) الجامعة بالمملكة العربية السعودية.

المراجع:

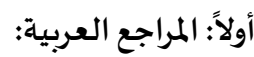

1. إسماعيل، إيهاب سيد(2020). التفكير الأخلاقي وعلاقته بالمسؤولية الإجتماعية لمدربي السباحة. المجلة العلمية للتربية البلدنية وعلوم الرياضية: 26(8): 1-24.

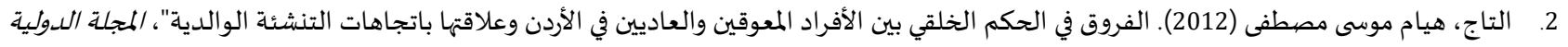

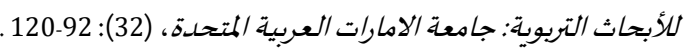

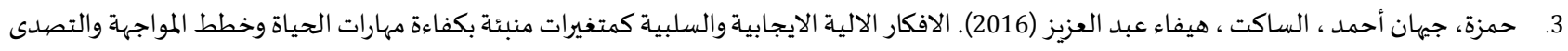

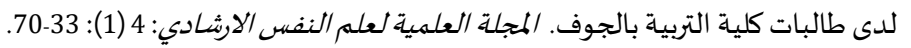
4.

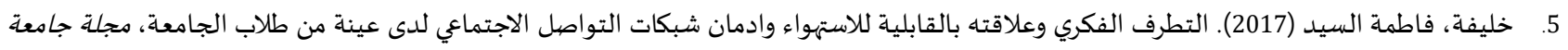

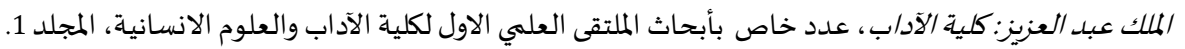

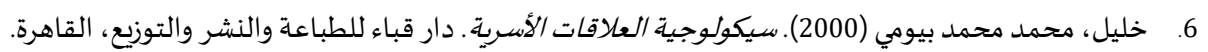

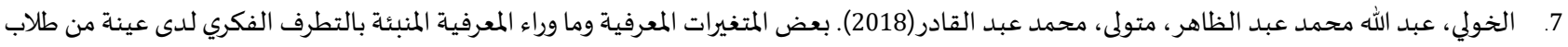

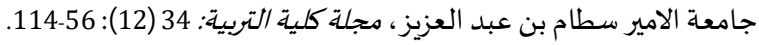


8. أبو دوابة، محمد محمود، عليان، محمد مصطفى (2012). الاتجاه نحو التطرف وعلاقته بالحاجات النفسية للدى طلبة جامعة الازهر بغنق، رسالة ماجستير، كلية التربية، جامعة الازهر، غزة .

9. $140-110:(4)$

10. الصبوة، محمد نجيب (2013). الانحراف الفكري وأثره على الأمن الوطني العامفي جمهورية مصر العببية. إطلالة نفسية بالجمعية المصرية للمعالجين النفسيين. 11. عبارة ، هاني محمد (2018). المناخ الأسري غير السوي وعلاقته بظهور بعض المشكلات الاجتماعية لدى المراهقين: دراسة ميدانية علي عينة من طلبة الثانوية العامة في مدينة حمص المصدر. مجلة جامعة القدس المفتوحة للأبحاث والدراسات التريوية والنفسية: 9 (25): 163-178. 12. عبد الفتاح، فوقية (2001). مقياس التفكير الأخلاقي للراشـين - كراسـة التعليمات. مكتبة الأنجلو، القاهرة. 13. عدس، عبد الرحمن، توق، مجي الدين (2000). اساسيات علم النفس التربوي. دار الفكر والتوزيع ،عمان ، الاردن. 14. على، نجوى حسين، حامد، سوزان (2012). فاعلية برنامج في تنمية التفكير الأخلافي لدى عينة من طالبات كلية التربية. مجلة العلوم التوبوية والنفسية: جامعة القصيم، 5(2): 155- 150.

15. قاسم، نعمات أحمد (2018). المرونة النفسية وعلاقتها بالتفكير الأخلاقي لدى عينة من طلاب الجامعة، المجلة التربوية: 54 : 677-714، كلية التربية، جامعة سوهاج ، مصربر

16. القاضي، بيان أكرم (2013). الأعراض النفسية والمرضية والمناخ الأسري والعلاقة بينهم للى طلبة جامعة اليرموك. رسالة ماجستير، كلية التربية ، جامعة اليرموك، الاردن .

17. كفافي، علاء الدين (1999). الاششاد والعلاج النفسي الأسري، القاهرة :دار الفكر العربي. 18. المدادحة، فاتن داؤد (2015). علاقة الضغوط النفسية بالتحصيل والتطرف الفكري وتقدير الندات لدى طلبة جامعة مؤته. رسالة ماجستير، كلية العلوم التربوية، الاردن

19. المعايضهة، حمزة (2020) ـ الإرهاب والتطرف الفكري (المفهوم -الدافع- سبل المواجهة). المجلة العببية للنشر العلهي: (23): 1-32. 20. مقدادي، يوسف موسى (2015). التفكير الخلقي وعلاقته بكل من الوجود النفسي والسلوك الاجتماعي الايجابي .المجلة الاردنية في العلوم التوبوية: 11(3): 269-

21. المهناء، فاطمة خاف (2012). المناخ الأسري وعلاقتـه بالتفكير الابداعي للدى طلبة جامعة الجوف. رسالة ماجستير، كلية التربية، جامعة اليرموك، الاردن. 22. ميطر ، عائشـة (2020) . فاعلية الذات وعلاقتها بالمناخ الأسري لدي المراهقين. مجلة سيسولوجيا للسوراسات والبحوث الإجتهاعية: 4 (2): 276-298.

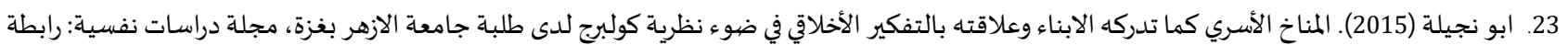
الاخصيائيين التفسيين المصريين، 25 (1): 93-151.

ثانياً: المراجع العربية:

1. Bureau, J. S., \& Mageau, G. A. (2014). Parental autonomy support and honesty: The mediating role of identification with the honesty value and perceived costs and benefits of honesty. Journal of Adolescence, 37(3): 225-236. https://doi.org/10.1016/j.adolescence.2013.12.007

2. Cleveland MJ, Gibbons FX, Gerrard M, Pomery EA \& Brody GH. (2005). The Impact of Parenting on Risk Cognitions and Risk

3. Behaviour: A study of Mediation and Moderation in a Panel of African American Adolescents. Child Development. 76(4): 900916. https://doi.org/10.1111/j.1467-8624.2005.00885.x

4. Coleman, J. (2014). Working With Troubled Adolescents- United States of America: International Psychotherapy Institute

5. Gibbs, J. C. (2003). Moral development and reality: Beyond the theories of Kohlberg and Hoffman. Thousand Oaks: Sage.

6. Lerner, R. (2002). Adolescence. Development, diversity, context, and application. New Jersey. Prentice, hall.

7. Moshman, D. (2005). Adolescent psychological development: Rationality, morality, and identity (2nd ed.). Mahwah, NJ: Lawrence ErIbaum Associates.

8. Palmer, E.J., \& Hollin, C. R. (2001). Sociomoral Reasoning, Perceptions of Parenting and Self-Reported Delinquency in Adolescents. Applied Cognitive Psychology, 15 (1): 85-100. https://doi.org/10.1002/1099-0720(200101/02)15:1\%3C85::aidacp691\%3E3.0.co;2-6

9. Ting, YU, San-Rong, XIAO \& Guang-Xin, XU. (2011). The Influence of Personality Traits, Family Environment on Middle School Students' Moral Judgment Competence. Psychological Science, 34(3): 664-669. 
المجلة الدولية للدراسـات التربوية والنفسية

International Journal of Educational \& Psychological Studies (EPS)

Journal Homepage: https://www.refaad.com/views/EPSR/Home.aspx

www.refaad.com

ISSN: 2520-4149 (Online) 2520-4130 (Print)

\title{
The role of the family climate in the relationship between the moral Thinking and intellectual extremism for a sample of female students in King Khalid University
}

\section{Sobhia Ahmed Abdel Qader Mohamed}

Assistant Professor, Department of Psychology, College of Education, King Khalid University, KSA drsobhia2010@gmail.com

\author{
Received : 3/6/2021 Revised : 30/6/2021 Accepted : 24/8/2021 DOI : https://doi.org/10.31559/EPS2021.10.3.10
}

Abstract: This study aims to identify the family atmosphere and its relationship to both moral thinking and intellectual extremism for a sample of female students in King Khalid University. The study includes (250) female students of scientific and literary specialties. The study includes the following hypotheses: 1 . What the moral thinking level for the study sample is. 2 . What the intellectual extremism level for the study sample is. 3 . If there is a related statistically significant relationship between the family atmosphere and moral thinking for the sample of the study. 4- If there is a related statistically significant relationship between the family atmosphere and the intellectual extremism for the sample of the study .5- If there is a related statistically significant relationship between moral thinking and the intellectual extremism for the sample of the study. 6- There are statistically significant differences between the female students in the family atmosphere because of the variable of specialty (scientific or literary).7- There are statistically significant differences between the female students in the moral thinking because of the variable of specialty (scientific or literary). 8- There are statistically significant differences between the female students in the intellectual extremism because of the variable of specialty (scientific or literary).9- It is predictable that the correlation degree between moral thinking and the intellectual extremism may change after statistical insulation of the family atmosphere. The following tools were applied: -The scale of the family atmosphere and the moral thinking prepared the researcher -The scale of the intellectual extremism prepared by Mujeddah Alkeshky (2016). The suitable statistical factors will be used to verify the validity of the study hypotheses. The most important recommendations were to continue taking care of the moral aspect of university students.

Keywords: familyatmosphere; moral reasoning; university students.

\section{References:}

1. 'barh, Hany Mhmd (2018). Almnakh Alasry Ghyr Alswy W'laqth Bzhwr B'd Almshklat Alajtma'yh Lda Almrahqyn: Drash Mydanyh 'ly 'ynh Mn Tlbh Althanwyh Al'amh Fy Mdynh Hms Almsdr. Mjlt Jam't Alqds Almftwhh Llabhath Waldrasat Altrbwyh Walnfsyh: 9 (25): 163-178.

2. 'bd Alftah, Fwqeh (2001). Mqyas Altfker Alakhlaqy Llrashdyn - Krast Alt'lymat. Mktbt Alanjlw, Alqahrh.

3. ' 'ds, 'bd Alrhmn, Twq,Mhy Aldyn (2000). Asasyat 'Im Alnfs Altrbwy. Dar Alfkr Waltwzy' ,'man , Alardn.

4. ' 'la, Njwa Hsyn, Hamd, Swzan (2012). Fa'lyt Brnamj Fy Tnmyt Altfkyr Alakhlaqy Lda 'ynh Mn Talbat Klyt Altrbyh. Mjlt Al'lwm Altrbwyh Walnfsyh: Jam't Alqsym, 5(2): 155- 250.

5. Abw Dwabh, Mhmd Mhmwd, 'lyan, Mhmd Mstfa (2012). Alatjah Nhw Alttrf W'laqth Balhajat Alnfsyh Lda Tlbh Jam't Alazhr Bghzh, Rsalt Majstyr, Klyt Altrbyh, Jam't Alazhr, Ghzh.

6. Esma'yl, Eyhab Syd(2020). Altfkyr Alakhlaqy W'laqth Balms'wlyh Alejtma'yh Lmdrby Alsbahh. Almjlh Al'lmyh Lltrbyh Albdnyh W'lwm Alryadh: 26(8): 1-24 .

7. Hmzh, Jyhan Ahmd, Alsakt, Hyfa' 'bd Al'zyz (2016). Alafkar Alalyh Alayjabyh Walslbyh Kmtghyrat Mnb'h Bkfa't Mharat Alhyah Wkhtt Almwajhh Waltsda Lda Talbat Klyt Altrbyh Baljwf. Almjlh Al'lmyh L'lm Alnfs Alarshady: 4 (1): 33-70.

8. Kfafy, 'la' Aldyn (1999). Alarshad Wal'laj Alnfsy Alasry, Alqahrh: Dar Alfkr Al'rby.

9. Khlyl, 'fra' brahym (2006). Almnakh Alasry W'laqth Balshh Alnfsyh Llabna'. Mjlt Klyt Altrbyh: Aljam'h Almstnsryh, (49): 483-507. 
10. Khlyfh, Fatmh Alsyd (2017). Alttrf Alfkry W'laqth Balqablyh Llasthwa' Wadman Shbkat Altwasl Alajtma'y Lda 'ynh Mn Tlab Aljam'h, Mjlt Jam't Almlk 'bd Al'ezyz: Klyt Aladab, 'dd Khas Babhath Almltqa Al'lmy Alawl Lklyt Aladab Wal'lwm Alansanyh, Almjld 1.

11. Alkhwly, 'bd Allh Mhmd 'bd Alzahr, Mtwla, Mhmd 'bd Alqadr(2018). B'd Almtghyrat Alm'rfyh Wma Wra' Alm'rfyh Almnb'eh Balttrf Alfkry Lda 'ynh Mn Tlab Jam't Alamyr Stam Bn 'bd Al'zyz, Mjlh Klyt Altrbyh: 34 (12): 56-114.

12. Alm'aydh, Hmzh (2020). Alerhab Walttrf Alfkry (Almfhwm -Aldaf'- Sbl Almwajhh). Almjlh Al'rbyh Llnshr Al'lmy: (23): 132.

13. Almdadhh, Fatn Da'd (2015). 'laqh Aldghwt Alnfsyh Balthsyl Walttrf Alfkry Wtqdyr Aldat Lda Tlbh Jam't M'th. Rsalt Majstyr, Klyt Al'lwm Altrbwyh, Alardn .

14. Almhna', Fatmh Khaf (2012). Almnakh Alasry W'laqth Baltfkyr Alabda'y Lda Tlbh Jam't Aljwf. Rsalt Majstyr, Klyt Altrbyh, Jam't Alyrmwk, Alardn.

15. Mqdady, Ywsf Mwsa (2015). Altfkyr Alkhlqy W'laqth Bkl Mn Alwjwd Alnfsy Walslwk Alajtma'y Alayjaby. Almjlh Alardnyh Fy Al'lwm Altrbwyh: 11 (3): 269-284.

16. Mytr, 'a'shh (2020). Fa'lyt Aldat W'elaqtha Balmnakh Alasry Lda Almrahqyn. Mjlh Syswlwjya Lldrasat Walbhwth Alejtma'yh: 4 (2): 276-298.

17. Abw Njylh (2015). Almnakh Alasry Kma Tdrkh Alabna' W'laqth Baltfkyr Alakhlaqy Fy Dw' Nzryt Kwlbrj Lda Tlbt Jam't Alazhr Bghzh, Mjlt Drasat Nfsyh: Rabtt Alakhsa'yyn Altfsyyn Almsryyn, 25 (1): 93-151.

18. Alqady, Byan Akrm (2013). Ala'rad Alnfsyh Walmrdyh Walmnakh Alasry Wal'laqh Bynhm Lda Tlbh Jam't Alyrmwk. Rsalt Majstyr, Klyt Altrbyh, Jam't Alyrmwk, Alardn .

19. Qasm, N'mat Ahmd (2018). Almrwnh Alnfsyh W'laqtha Baltfkyr Alakhlaqy Lda 'ynh Mn Tlab Aljam'h, Almjlh Altrbwyh: 54: 677-714, Klyt Altrbyh, Jam't Swhaj, Msr.

20. Alsbwh, Mhmd Njyb (2013). Alanhraf Alfkry Wathrh 'la Alamn Alwtny Al'am Fy Jmhwryh Msr Al'rbyh. Etlalh Nfsyh Baljm'yh Almsryh Llm'aljyn Alnfsyyn.

21. Slamh, 'qyl Slamh, Frj, 'bdalftah (2016). Almrwnh Alm'rfyh W'eaqtha Balttrf Alfkry Lda Tlbt Jam't Alamyr Stam Bn 'bdal'zyz. Mjlt Klyt Altrbyh: 32 (4): 110-140.

22. Altaj, Hyam Mwsa Mstfa (2012). Alfrwq Fy Alhkm Alkhlqy Byn Alafrad Alm'wqyn Wal'adeen Fy Alardn W'laqtha Batjahat Altnsh'h Alwaldyh", Almjlh Aldwlyh Llabhath Altrbwyh: Jam't Alamarat Al'rbyh Almthdh,(32): 92-120 . 